\title{
La cosecha de El Garcel (Antas, Almería): estructuras de almacenamiento en el sureste de la península ibérica*
}

\author{
The harvest of El Garcel: storage pits in the Southeast of Spain
}

\author{
María de la Paz Román Díaz y Ruth Maicas Ramos
}

\section{RESUMEN}

Nuestro estudio de El Garcel, uno de los yacimientos más importantes de la prehistoria española, está basado en la documentación y materiales de la Colección Siret del Museo Arqueológico Nacional. Se presentan nuevas dataciones por Termoluminiscencia. A la luz de la nueva información sobre sus estructuras y materiales obtenida para este trabajo, ofrecemos una perspectiva diferente sobre el periodo de ocupación de El Garcel y sus rasgos espaciales, así como sobre las actividades realizadas en el yacimiento. Esto nos permite desarrollar una nueva perspectiva sobre el papel socio-económico del yacimiento en el sureste español durante la Prehistoria.

\begin{abstract}
Our new study of El Garcel, one of the most important sites in Spanish prehistory, is based on the documentation and materials in the Siret collection of the Museo Arqueológico Nacional. New Thermoluminiscence dates based are presented. In light of the new information about structures and materials obtained for this paper, we offer a different perspective on the El Garcel's time of occupancy, its spatial features, as well as on activities carried out at the site. This permits us to develop a new perspective on the site's socio-economic role in prehistoric south-east Spain.
\end{abstract}

Palabras clave: Silos; Termoluminiscencia; Sureste de la Península Ibérica; Neolítico; Calcolítico; Edad del Bronce; IV, III y II milenio a. C.
Key words: Storage pits; Thermoluminiscence; Southeast Spain; Neolithic; Chalcolithic; Bronze Age; IV, III and II millennium $B C$.

\section{INTRODUCCIÓN}

El Garcel es un yacimiento arqueológico del sureste de la península ibérica también conocido como Aljoroque o Algarce, situado a menos de $1 \mathrm{~km}$ al sureste del núcleo urbano de Antas (Almería) (Fig. 1). Se le nombra reiteradamente como uno de los más relevantes de la Prehistoria Reciente, pero ha habido escasas aportaciones tras las de Luis y Enrique Siret y Cels a finales del siglo XIX. Entre 1888 y 1890 se hicieron excavaciones supervisadas por L. Siret y llevadas a cabo por Pedro Flores. Generaron una amplia documentación inédita y recuperaron una gran cantidad de material arqueológico que, en su mayoría ${ }^{1}$, está en los fondos del Museo Arqueológico Nacional (MAN) en Madrid. L. y E. Siret publicaron unas breves descripciones del yacimiento y de sus materiales en Las Primeras Edades del Metal (Siret y Siret 1890). L. Siret escribió el estudio más detenido, "L’Espagne Préhistorique", en 1891 pero permaneció inédito hasta 2001 (Siret 2001), aunque continuó haciendo referencias al yacimiento en trabajos posteriores.

El Garcel es de gran interés para el estudio del poblamiento del sureste por el tipo y cantidad de estructuras excavadas y el material hallado. L. Siret dio

\footnotetext{
* En el presente trabajo, tres dataciones de autentificación por Termoluminiscencia fueron subvencionadas por el proyecto I+D: "Poblamiento y Territorio en la Cuenca del Alto Almanzora desde la Prehistoria a la Época Medieval: transformaciones y pervivencias" (Ref. BHA2000-1228), Ministerio de Ciencia e Innovación. IP: Catalina Martínez Padilla.

a Área de Prehistoria, Dpto. Geografía, Historia y Humanidades. Facultad de Humanidades. Universidad de Almería. Carretera Sacramento s/n. 04120 La Cañada de San Urbano. Almería Correo e.: mproman@ual.es https://orcid.org/0000-0002-1866-2286

b Dpto. Prehistoria. Museo Arqueológico Nacional. C/ Serrano 13.28001 Madrid. Correo e.: ruth.maicas@mecd.es https://orcid.org/0000-0001-6093-1016 Recibido: 27-VI-2017; aceptado: 3-VIII-2017.

${ }^{1}$ Otras instituciones con materiales de El Garcel: Musées Royaux d'Art et d'Histoire de Bruselas, British Museum y Museo de Almería.
} 


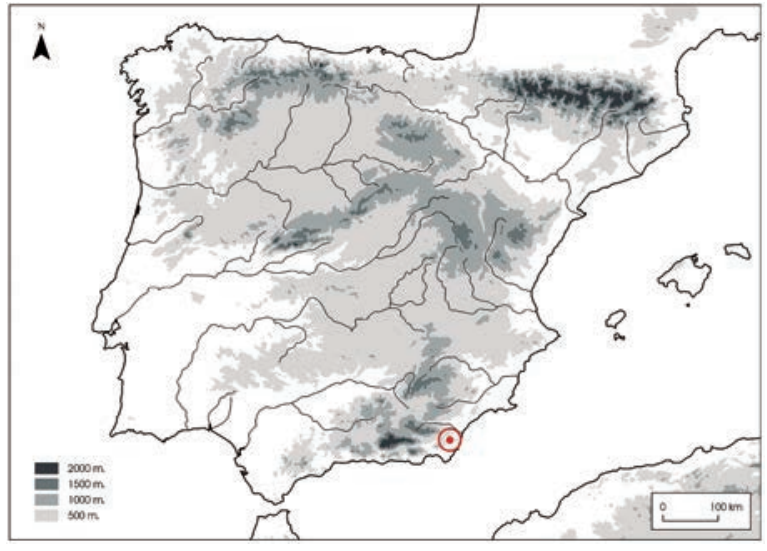

Fig. 1. Localización del yacimiento de El Garcel I y II (Antas, Almería) en la Península Ibérica.

cuenta de ello y planteó la existencia de un período "garceliano", definido por el carácter arcaico de su industria lítica (Siret 1999: 307).

En 1941, Guillermo Gossé (1941), publicaba como suyo un estudio monográfico del yacimiento reproduciendo las láminas y el texto inédito de "L'Espagne Préhistorique" (Martín 2001). Los resultados de las excavaciones posteriores de Julio Martínez Santa-Olalla permanecieron inéditos y los de la excavación de Pilar Acosta en 1973, la última realizada, se publicaron en un breve informe (Acosta 1976).

Los pocos datos conocidos de El Garcel no han impedido su cita recurrente como referente sobre las sociedades de la tradicional "Cultura de Almería" (Román 1996). Nuestro propósito al estudiar la documentación y los materiales de la colección Siret del MAN, en su mayoría descontextualizados, es aportar nuevas dataciones y aproximarnos a la interpretación del yacimiento. Dada la amplitud de esta empresa, analizaremos en especial las estructuras, considerando tanto sus características como la información aportada por los elementos muebles documentados en el interior de las mismas.

\section{EMPLAZAMIENTO Y ENTORNO ACTUAL}

El Garcel ha sido descrito como un emplazamiento único cuando, en realidad, se asienta sobre dos mesetas independientes, consignadas como "Garcel I" y "El Garcel II" o "Segundo Llano de El Garcel". Las bases para esta afirmación son la asignación por L. Siret de los materiales (12.668 piezas) a la "meseta principal" (Siret 2001: 87), luego debía haber "otra/s". Cuando se dibujan, se remiten a una u otra área, ya sea con el término completo o abreviado ( $\mathrm{G} 1$ o G2). Por último,
P. Flores distinguió ambos llanos en sus diarios de excavación, les asignó una numeración independiente y dibujó un croquis de cada uno de los emplazamientos. A pesar de no ser los dibujos de un profesional, ambos son identificables en la topografía local, tanto en los mapas recientes a escala 1:10.000 (Fig. 2) como en las imágenes de satélite de Google Maps (Fig. 3) ${ }^{2}$.

L. Siret no tuvo en cuenta esta primigenia diferenciación y unió ambos conjuntos tanto en "L'Espagne Préhistorique" como en Las Primeras Edades del Metal. En nuestro estudio, respetamos esta decisión final, pero mantenemos la referencia precisa a cada conjunto en el análisis de estructuras y materiales, en un intento de hallar una explicación espacial, temporal o funcional de esta dualidad.

El Garcel I es la meseta descrita por P. Acosta (1976: 190) que estimó su superficie en $5.000 \mathrm{~m}^{2}$. El eje máximo, orientado Norte-Sur, tiene unos $170 \mathrm{~m}$ y los ejes Este-Oeste oscilan entre 30 y $70 \mathrm{~m}$. El Garcel II se situaría a $50 \mathrm{~m}$ al sureste de El Garcel I, con unos $1.200 \mathrm{~m}^{2}$ de superficie. Ambas mesetas están a unos $30 \mathrm{~m}$ de altura sobre el río Antas (Figs. 2 y 3).

Según los estudios antracológicos de los yacimientos de la Depresión de Vera (Rodríguez Ariza 2000), donde se encuentra dicho río, la vegetación era más abundante y variada en el III milenio a.C. Estaba formada por un matorral más o menos denso de lentiscos y acebuches junto al que existían zonas de matorral abierto con pinos carrascos; los fondos de los valles estarían ocupados por los campos de cultivo sustituidos junto a los cauces por vegetación de ribera.

El río Antas, de régimen torrencial, tiene una vega formada fundamentalmente por depósitos aluviales de origen cuaternario, el resto son areniscas y margas del Mioceno. Los cultivos posibles sobre las mesetas son los cereales de invierno (trigo, cebada, avena, etc.) y las leguminosas (judías, habas, lentejas, veza, almorta, etc.) en siembra otoñal. P. Acosta comprobó en 1973 restos de cultivo de centeno en zonas que actualmente se dedican a pastizal/matorral. La vegetación es achaparrada y dispersa, con espartos, en el entorno inmediato al yacimiento (MAPA 1978).

L. y E. Siret constataron la escasa potencia estratigráfica de El Garcel (Siret y Siret 1890: 6) y P. Acosta (1976) huellas de las antiguas excavaciones de L. Siret y Martínez Santa-Olalla o de expolio. El emplazamiento de El Garcel I goza de protección legal ${ }^{3}$.

\footnotetext{
${ }^{2}$ Las coordenadas UTM de un punto central de cada meseta son El Garcel I: 596650/4122600 y El Garcel II: 596789/4122465 (Instituto de Cartografía de Andalucía, Mapa Topográfico 1:10.000, hoja 1014-4-3).

${ }^{3}$ El Garcel I es Bien de Interés Cultural desde 1/07/1992 y, según las Normas Complementarias o Subsidiarias de Planeamiento, se aprobó definitivamente la Zona Arqueológica con el nivel de protección Tipo 1 el 24/09/1993. Catálogo de Yacimientos Arqueológicos de la Delegación Provincial de Almería, Consejería de Cultura, Junta de Andalucía
} 


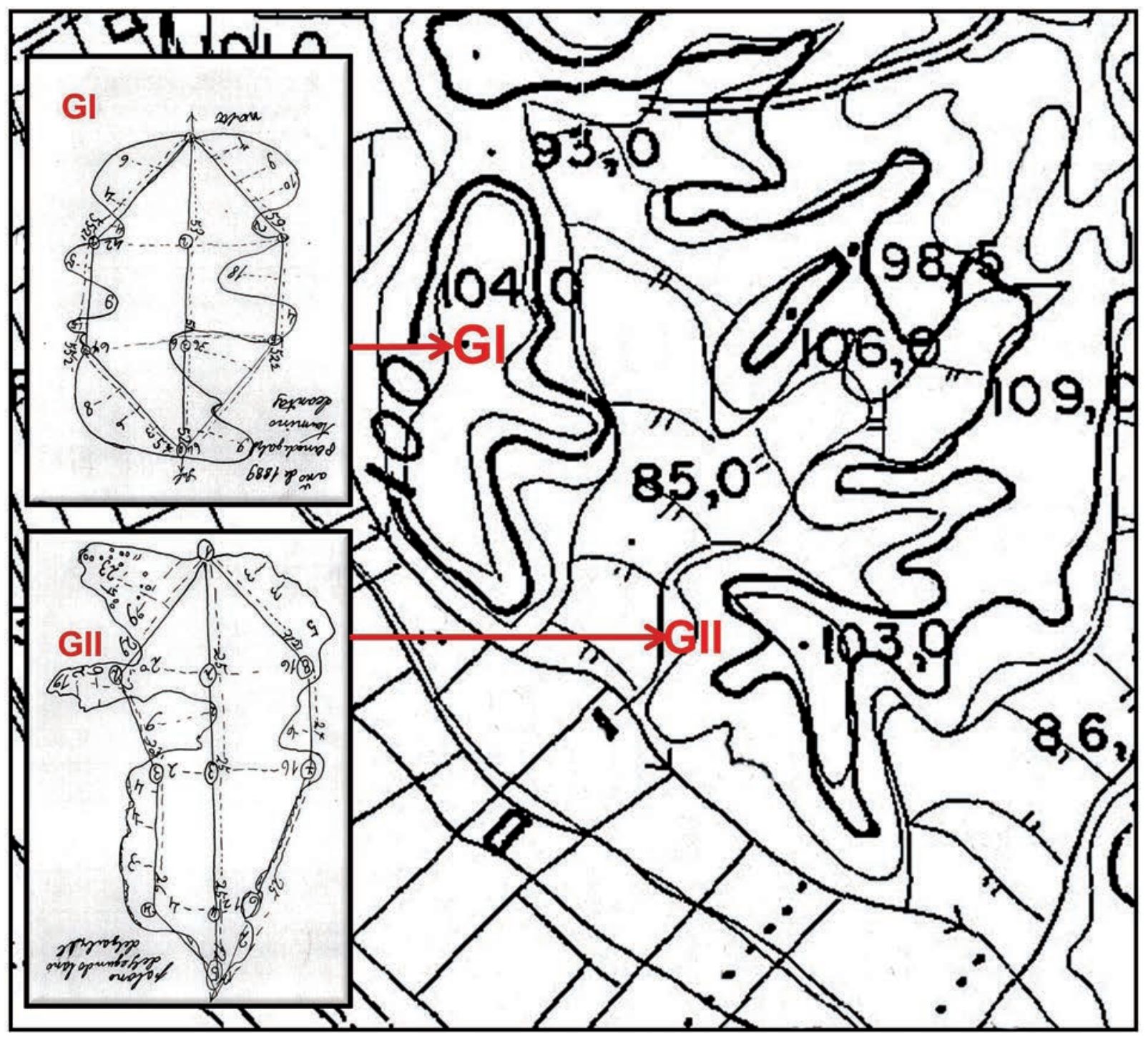

Fig. 2. Planos de Pedro Flores de El Garcel I y II (Antas, Almería), orientados hacia el norte. Cuadernos de Pedro Flores. Archivo del Museo Arqueológico Nacional. Las flechas indican la posición topográfica de las dos mesetas de El Garcel (a partir de "Provincia de Almería". Mapa Topográfico de Andalucía digital del Instituto de Cartografía de Andalucía 1998, escala 1:10.000 Mosaico Raster (hoja 1014-4-3), curvas de nivel cada $10 \mathrm{~m}$ de altura).

\section{DOCUMENTACIÓN}

El Archivo Siret del MAN está formado por manuscritos, dibujos, bocetos, planos, alzados y listados de materiales escritos por L. Siret, así como por un amplio epistolario. Se conservan también datos de los embalajes realizados en Herrerías (Almería) y en Barcelona, y documentos generados tras la muerte de los hermanos Siret.

La documentación más interesante para este estudio son los seis diarios de excavación redactados por P. Flo- res y sus hijos entre 1888 y 1890 (Cuadernos XXIV a XXVIII para El Garcel I y XXXVI para El Garcel II), así como una carpeta con anotaciones y documentación gráfica de L. Siret. En ella se conservan notas escritas sobre diferentes soportes. Otros documentos, hoy dispersos, en origen debieron estar agrupados bajo esta cubierta.

La información recogida permite reconstruir el contenido, número y características de los "hoyos" (así denominaba P. Flores a las estructuras). Sorprende la discrepancia existente entre el volumen de materiales 
adjudicados a las estructuras y a El Garcel. Se conservan con referencia a hoyos de El Garcel I y de El Garcel II, poco más de 1.000 piezas (1.070 números de inventario), pero tenemos cerca de 19.000 piezas sin referencia a estructura o nivel. Atribuimos la diferencia a que la mayor parte de los objetos recuperados en las excavaciones correspondían a un nivel carente de estructuras ya que, según los Siret, los vestigios prehistóricos yacían a poca profundidad, y la mayor parte hasta en la misma superficie, sin señal de construcciones, tan sólo alguna tierra carbonosa (Siret y Siret 1890: 6). Todo el Cuaderno XXIV corresponde a dibujos de materiales sin referencia; la asignación a estructuras comienza en el Cuaderno XXV.

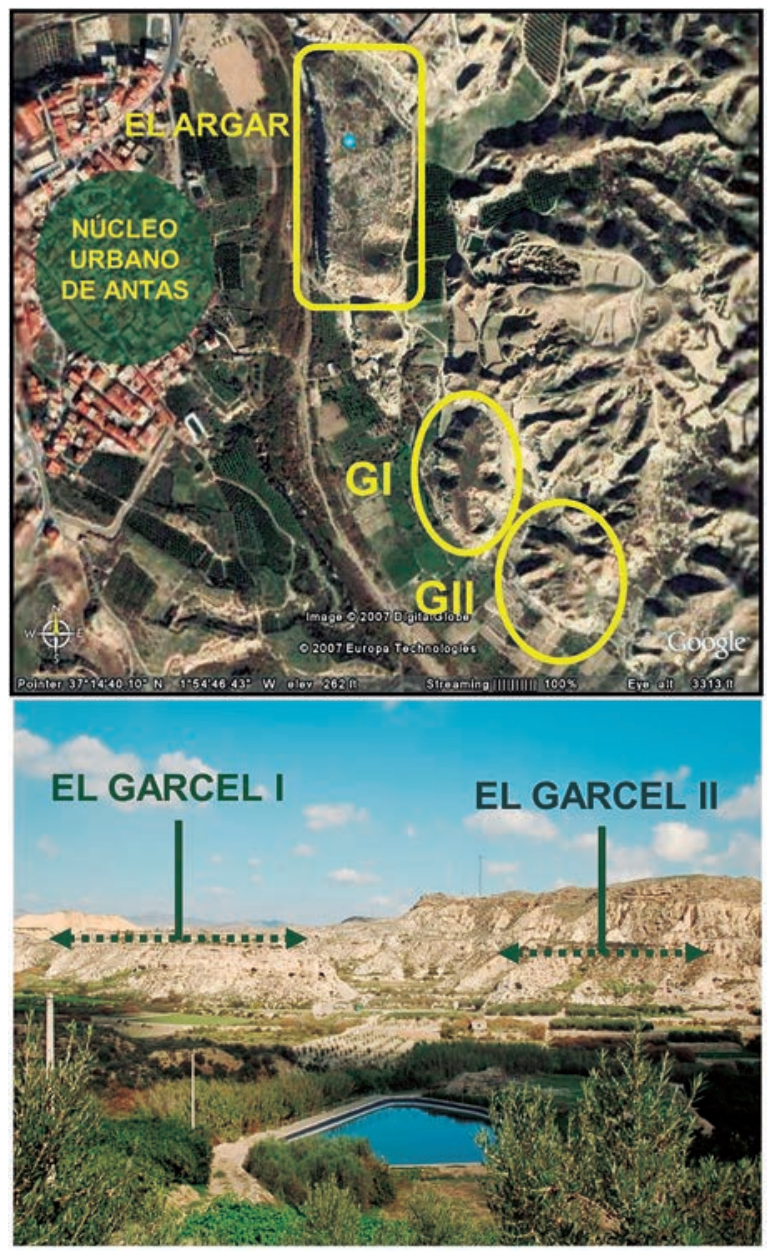

Fig. 3. Arriba: localización de los yacimientos de El Argar, El Garcel I y El Garcel II junto al núcleo urbano de Antas (Almería) (a partir de Google Maps https://www.google.es/maps/@37.2426169,$1.9104865,456 \mathrm{~m} /$ data $=! 3 \mathrm{~m} 1 ! 1 \mathrm{e} 3)$. Abajo: vista desde el sur de las mesetas de El Garcel I y II (foto M ${ }^{\text {a }}$ Paz Román Díaz, en color en la edición electrónica).

\section{EL COMPLEJO CONTEXTO CRONOLÓGICO DE EL GARCEL}

La cronología relativa y absoluta de El Garcel es controvertida. Según la periodización tradicional, las propuestas generalmente han oscilado entre el Neolítico final y el Calcolítico. El principal problema era la presencia conjunta, pero sin contexto estratigráfico claro, de dos tipos de materiales considerados indicadores cronológicos de dos períodos distintos y distantes en el tiempo: una industria lítica "poco evolucionada" (geométricos) del Epipaleolítico, escorias descontextualizadas y algún útil de cobre atribuido al Calcolítico.

Las dataciones realizadas en los años 70 y 80 , no resolvieron el conflicto. Dos de ellas situaron el yacimiento en torno al 2000 a.C. y una tercera resultó muy reciente, por lo que fue excluida (Mederos 1995) e incluso las tres llegaron a ser rechazadas (Castro et al. 1996): $4120 \pm 100 \mathrm{BP}(2850-2620 \mathrm{cal} \mathrm{AC}): 2170$ \pm 100 a.C. SUA-1173 y $3850 \pm 70 \mathrm{BP}(2290 \mathrm{cal} \mathrm{AC})$ : $1900 \pm 170$ a.C. SUA-2145, ambas sobre muestras de concha, procedentes de terreras de excavaciones antiguas y 1220 BP CSIC-252 sobre madera, recuperada en las excavaciones de P. Acosta.

El estado de la cuestión hacía recomendable realizar nuevas dataciones. Por ello recurrimos a la técnica de Autentificación por Termoluminiscencia (TL) llevada a cabo en el Laboratorio de Termoluminiscencia de la Universidad Autónoma de Madrid. Las fechas absolutas obtenidas son los años transcurridos desde la última vez que el material cerámico sufrió un proceso de calentamiento enérgico (cocción).

Seleccionamos tres muestras de recipientes cerámicos de El Garcel I con un contexto seguro, es decir, descritas y/o dibujadas por P. Flores y por L. Siret y correspondientes a estructuras numeradas ("hoyos"): dos fragmentos de vasijas de almacenamiento ("tinajas") de las estructuras 30 y 52 y un tercero de una copa reconstruida por el propio L. Siret (o por G. Gosse), perteneciente a la estructura 146 (Tab. 1).

Las nuevas dataciones absolutas obtenidas marcan un período de tiempo entre finales del IV milenio a.C. y finales del II milenio $(5058 \pm 364$ a $3076 \pm 215$ años desde la última cocción, Tab. 1). Por lo tanto, las dataciones previas, a pesar de su descontextualización, vienen a estar dentro del amplio marco cronológico indicado por las fechas de TL (a excepción de la más reciente, $1220 \mathrm{BP}, \mathrm{CSIC}-252$ ).

Estamos pues, ante una longeva práctica de construcción de estructuras tipo "fosa", de al menos unos dos mil años, con diferentes funciones, de las que cabe destacar la de almacenamiento observada también en otros yacimientos del sur peninsular (La Loma de Íllora en Granada, Campo de Hockey en San Fernando-Cádiz, Papa Uvas en Aljaraque-Huelva o Las Eras en Úbeda-Jaén) (Tab. 2).

Trab. Prehist., 75, N. ${ }^{\circ}$ 1, enero-junio 2018, pp. 67-84, ISSN: 0082-5638

https://doi.org/10.3989/tp.2018.12204 


\begin{tabular}{|c|c|c|}
\hline Muestra & Fecha & Localización \\
\hline MADN6298.BIN & $5058 \pm 364$ & $1984 / 156 /$ Gar1/30/1. Fondo de tinaja. Estructura 30 de El Garcel I \\
\hline MADN6300.BIN & $4048 \pm 268$ & $1984 / 156 /$ Gar1/146/2. Copa. Estructura 146 de El Garcel I \\
\hline MADN6299.BIN & $3076 \pm 215$ & $1984 / 156 /$ Gar1/52/6. Fondo de tinaja. Estructura 52 de El Garcel I \\
\hline
\end{tabular}

Tab. 1. Nuevas dataciones absolutas mediante Autentificación por Termoluminiscencia. Análisis realizados sobre muestras cerámicas en junio de 2013. Laboratorio de Termoluminiscencia del Laboratorio de Datación y Radioquímica de la Universidad Autónoma de Madrid.

\begin{tabular}{|c|c|c|c|}
\hline Yacimiento & Muestra & Fecha BP & Material \\
\hline Retamar & Beta-90122 & $6780 \pm 80$ & Concha \\
\hline La Loma & Beta-296955 & $6750 \pm 40$ & Concha \\
\hline La Loma & Beta-296958 & $5680 \pm 40$ & Concha \\
\hline La Loma & Beta-296957 & $5660 \pm 40$ & Concha \\
\hline Campo de Hockey & CNA-664 & $5650 \pm 40$ & Concha \\
\hline Pago de Cantarranas & ITN-1659 & $5490 \pm 50$ & No disponible \\
\hline El Garcel & MADN6298.BIN & $5058 \pm 364(2013 \mathrm{TL})$ & Cerámica \\
\hline Polideportivo de Martos & $\mathrm{I}-17083$ & $5080 \pm 140$ & Carbón \\
\hline La Loma & Beta-296954 & $5030 \pm 40$ & Carbón \\
\hline Pago de Cantarranas & UGR-370 & $4950 \pm 60$ & No disponible \\
\hline La Loma & Beta-296956 & $4920 \pm 40$ & Concha \\
\hline Papa Uvas & CSIC-485 & $4840 \pm 120$ & No disponible \\
\hline Pago de Cantarranas & UGR-369 & $4800 \pm 90$ & No disponible \\
\hline Las Eras & Beta-229721 & $4780 \pm 80$ & Cereal \\
\hline Polideportivo de Martos & CNA-607, 610-614, 616,617,621 & $4630 \pm 50$ a $4500 \pm 40$ & Fauna \\
\hline $\mathrm{C} /$ Floridablanca & No disponible & $4620 \pm 35$ & Carbón \\
\hline Las Eras & Ua-26017 & $4495 \pm 40$ & Cereal \\
\hline Papa Uvas & CSIC-812 & $4480 \pm 70$ & No disponible \\
\hline Papa Uvas & CSIC-811 & $4470 \pm 70$ & No disponible \\
\hline Las Eras & Ua-229720 & $4470 \pm 70$ & Cereal \\
\hline Polideportivo de Martos & CNA-603 & $4465 \pm 25$ & Fauna \\
\hline Polideportivo de Martos & CNA-618 & $4460 \pm 30$ & Fauna \\
\hline Las Eras & Beta-229719 & $4420 \pm 60$ & Cereal \\
\hline Papa Uvas & ICEN-1069 & $4420 \pm 90$ & Fauna \\
\hline Papa Uvas & ICEN-1079 & $4420 \pm 105$ & Concha \\
\hline Las Eras & Ua-34705 & $4415 \pm 35$ & Cereal \\
\hline Papa Uvas & ICEN-1073 & $4390 \pm 110$ & Concha \\
\hline Papa Uvas & ICEN-1068, 1075, 814, 1081 & $4380 \pm 110$ a $4320 \pm 105$ & Fauna y concha \\
\hline Polideportivo de Martos & CNA-620 & $4295 \pm 40$ & Fauna \\
\hline El Garcel & SUA-1173 & $4120 \pm 100$ & Hueso \\
\hline $\mathrm{C} /$ Floridablanca & No disponible & $4100 \pm 35$ & Carbón \\
\hline EI Garcel & MADN6300.BIN & $4048 \pm 268(2013 \mathrm{TL})$ & Cerámica \\
\hline El Garcel & SUA-2145 & $3850 \pm 70$ & Concha \\
\hline El Garcel & MADN6299.BIN & $3076 \pm 215(2013 \mathrm{TL})$ & Cerámica \\
\hline
\end{tabular}

Tab. 2. Distribución combinada de las dataciones entre el V y II milenio a.C. de yacimientos de fosas del sur de la península ibérica (a partir de Aranda et al. 2012). 


\section{ANÁLISIS DE LAS ESTRUCTURAS}

La documentación consultada nos ha permitido manejar variables relacionadas con la forma, volumen, número de estructuras, sustrato y técnicas de aislamiento, así como aproximarnos a su función.

\subsection{Número, forma y volumen de las estructuras}

L. Siret indicaba la existencia de "... más de trescientas cavidades" (Siret 2001: 75), pero sólo fueron documentadas 254 entre El Garcel I (202) y El Garcel II (52).

En nuestro recuento hemos considerado que L. Siret y $\mathrm{P}$. Flores emplearon un único número para estructuras que se cortaban unas a otras: "dobles" (Fig. 4A), "triples" e incluso una "quíntuple" (Fig. 4B). Según L. Siret estas intersecciones entre hoyos, que también documentó durante sus excavaciones en Almizaraque (Cuevas del Almanzora, Almería) (Fig. 5) son resultado de una sucesión en el tiempo. Tales estructuras
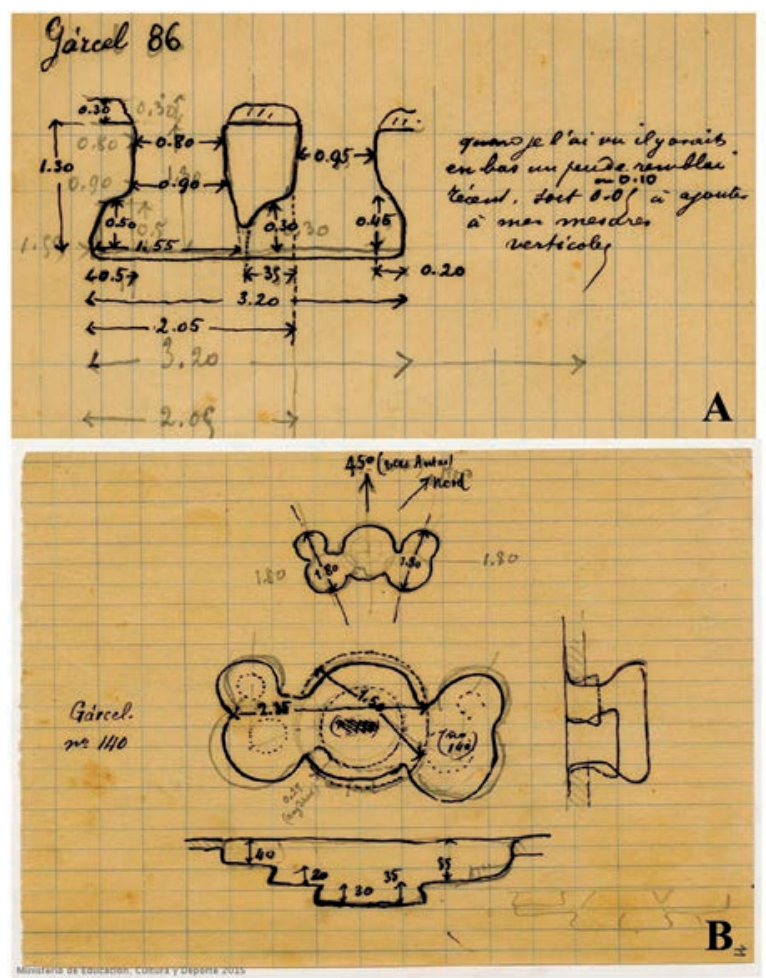

Fig. 4. El Garcel I (Antas, Almería): A) Sección de los "hoyos" geminados no 86 MANF1944_45 FD00746_SEQ 012_P. B) Sección del "hoyo" no 140 MANF1944_45_FD00746_SEQ_011_P. Archivo del Museo Arqueológico Nacional http://ceres.mcu.es/ (dibujos de Luis Siret) (en color en la edición electrónica). geminadas constituyen un pequeño conjunto respecto al total: 16 de 202 en El Garcel I (casi un 8\%) y 2 de 52 en El Garcel II (4\%). Las superficies limitadas de ambas mesetas debieron obligar a construir las fosas cada vez más cerca.

Para calcular el volumen de las estructuras hemos definido tres tipos geométricos - cilíndrico, troncocónico y cóncavo- a partir de las medidas facilitadas por P. Flores y de las secciones de la lámina 25 de L. Siret (2001). Solo el tipo troncocónico tiene documentación gráfica.

La forma cilíndrica se ha asignado a las estructuras de las que P. Flores indica un solo diámetro (suponemos el mismo para base y boca). La forma troncocónica corresponde a las estructuras que contaban con dos diámetros de distinta medida. Según los dibujos de L. Siret de las secciones de algunas estructuras, podemos estar ante dos subtipos: uno con forma acampanada del que dibujó la número 108 (Fig. 6A) y la 109 (Siret 2001: lám. 25, I) y otro con forma de botella de cuello largo, marcado, y cuerpo globular, similar a un "matraz", del que dibujó la número 86 (Fig. 4A) y la 166 (Fig. 6B). La forma cóncava (mayor diámetro de la boca que del fondo) es poco frecuente. Podría ser consecuencia de la destrucción de la boca de cualquiera de las formas mencionadas (Siret 2001: 75) o tener una función/origen distinto.

La proporción de formas cilíndricas y troncocónicas es muy similar en ambas mesetas (Tab. 3) a pesar de haber más estructuras en El Garcel I. Aquí suponen un $96 \%$ y en El Garcel II un 98\%. Cada tipo desglosado se acerca al 50\% en ambas mesetas, salvo el tipo cilíndrico en El Garcel II, un poco más presente.

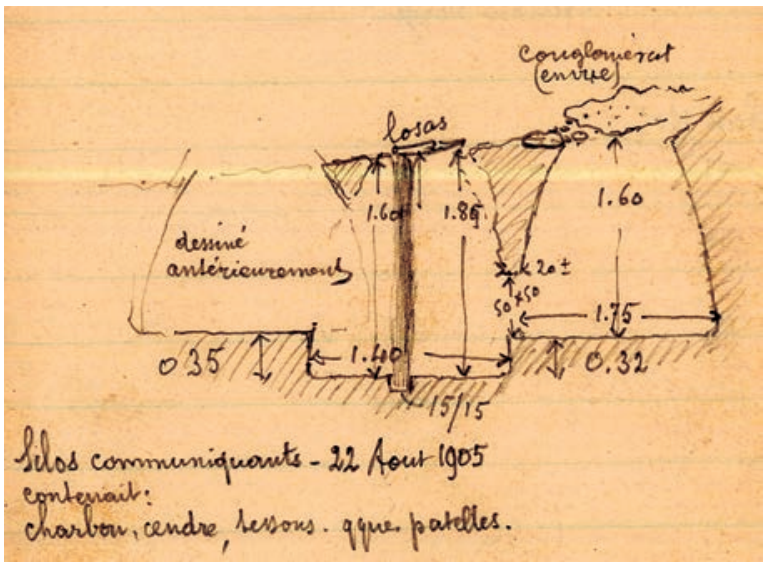

Fig. 5. Detalle de la sección de silos comunicantes de Almizaraque (Cuevas del Almanzora, Almería) (dibujo de Luis Siret). Archivo del Museo Arqueológico Nacional MANF1944/45/FD01364_076v077r-ID001, http://ceres.mcu.es/ (en color en la edición electrónica). 
Una vez definidos los tipos nos preguntamos si podrían haberse dispuesto espacialmente de alguna manera significativa. Como recordaremos, P. Flores
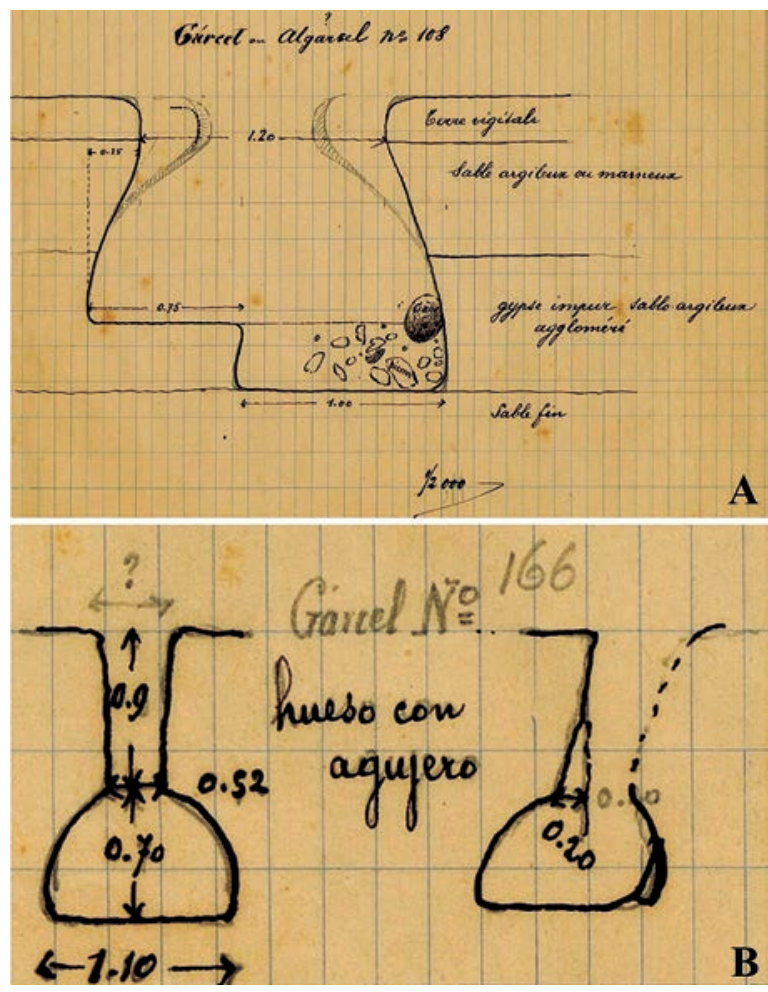

Fig. 6. El Garcel I (Antas, Almería): A) Corte estratigráfico del "hoyo" no 108, MANF1944_45_FD00746_SEQ_013_P. B) Detalle de dos secciones de la estructura no 166 , tipo "matraz", MANF1944_45 FD00746_SEQ_012_P. Archivo del Museo Arqueológico Nacional http://ceres.mcu.es/ (dibujos de Luis Siret, en color en la edición electrónica).

\begin{tabular}{|c|c|c|c|c|c|}
\hline & 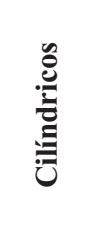 & 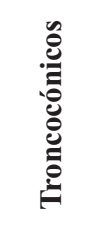 & 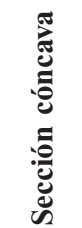 & 总 & ڤ్ \\
\hline GI & $\begin{array}{c}97 \\
(48 \%)\end{array}$ & $\begin{array}{c}97 \\
(48 \%)\end{array}$ & $\begin{array}{c}5 \\
(2 \%)\end{array}$ & $\begin{array}{c}3 \\
(2 \%)\end{array}$ & 202 \\
\hline GII & $\begin{array}{c}29 \\
(56 \%)\end{array}$ & $\begin{array}{c}22 \\
(42 \%)\end{array}$ & $\begin{array}{c}1 \\
(2 \%)\end{array}$ & $\begin{array}{c}0 \\
(0 \%)\end{array}$ & 52 \\
\hline Total & $\begin{array}{c}126 \\
(50 \%)\end{array}$ & $\begin{array}{c}119 \\
(47 \%)\end{array}$ & $\begin{array}{c}6 \\
(2 \%)\end{array}$ & $\begin{array}{c}3 \\
(1 \%)\end{array}$ & 254 \\
\hline
\end{tabular}

Tab. 3. Formas de las estructuras en El Garcel I y II (Antas, Almería): número y porcentaje. realizó unos "croquis" de los emplazamientos de El Garcel I y El Garcel II (Fig. 2), y en sus diarios indicó la distancia entre algunos "hoyos" y las "estacas" de referencia, pero no la dirección. Ello ha hecho imposible recomponer un plano con la localización de cada fosa. Sin embargo sus datos permiten inferir, gracias a las distancias indicadas, la existencia de grupos de cuatro a diez hoyos similares, especialmente en El Garcel I ${ }^{4}$. Sabemos que cualquier interpretación requeriría, lógicamente, conocer la cronología de cada estructura, pues la proximidad no implica necesariamente contemporaneidad. Podría deberse también a razones como un mismo tipo de contenido, la protección bajo una misma estructura o incluso, si contemplamos una posible causa social, pertenecer a una misma unidad doméstica.

Hemos agrupado las estructuras según su volumen para observar posibles pautas de preferencia por formas o tamaños (Díaz-del-Río et al. 1997; Pujante 1999). Los resultados son aproximados ya que partimos de cálculos basados en formas geométricas ideales.

Las agrupaciones del gráfico (Fig. 7) muestran una distribución equilibrada en El Garcel II frente a un predominio de las estructuras menores en El Garcel I. En general, los volúmenes más constatados están entre 300 y 1.2001 (especialmente entre 600 y 9001 ), es decir, no estamos ante grandes volúmenes. La media, unos $600 \mathrm{l}$, es similar a la de otros yacimientos del sureste peninsular como Las Palas en Cuevas de Almanzora, Almería (Román y Maicas 2002), Molinos

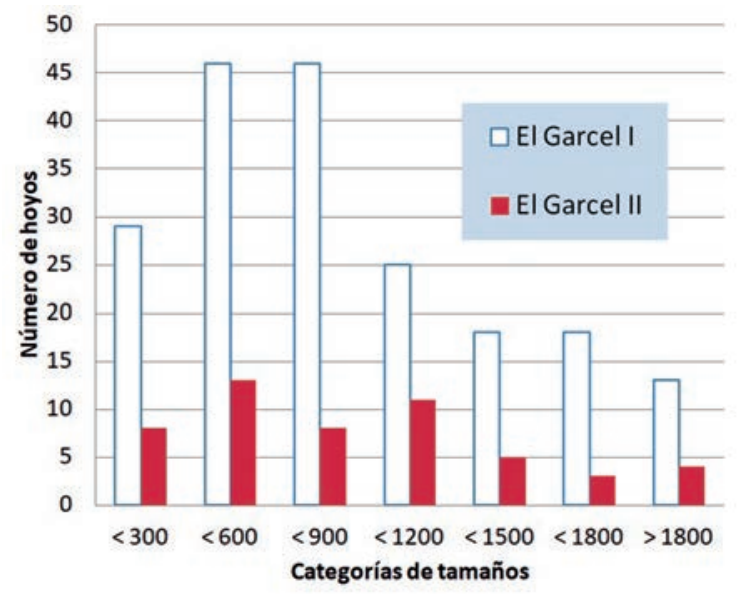

Fig. 7. Distribución de volúmenes de las estructuras de El Garcel I y El Garcel II (Antas, Almería) por intervalos (en color en la edición electrónica).

${ }^{4}$ Por ejemplo las estructuras de forma cilíndrica: 8 a 13,22 b a 30 , 70 a 74,113 a 122,135 a 143 y de forma troncocónica: 43 a 56a, 107 a 112,169 a 175 . 
de Papel en Caravaca, Murcia (Pujante 1999) o los de la Calle Floridablanca de Lorca, Murcia (Martínez y Ponce 1997).

Respecto a los tamaños, salvo excepciones, los diámetros en El Garcel I oscilan entre 50 y $175 \mathrm{~cm}$ y la profundidad entre 30 y $150 \mathrm{~cm}$. En El Garcel II los diámetros varían entre 50 y $150 \mathrm{~cm}$ y la profundidad entre 30 y $130 \mathrm{~cm}$. En consecuencia, los volúmenes de algunas estructuras de El Garcel I son mucho mayores que los de El Garcel $\mathrm{II}^{5}$.

De las tres dataciones de TL, la más reciente pertenece a la estructura de mayor tamaño por lo que cabe la posibilidad de que el volumen también pueda estar relacionado con la antigüedad. En ese caso, las distintas formaciones sociales sucedidas en El Garcel a lo largo de esos dos milenios puede que incrementaran la capacidad de las estructuras. Las muestras de las datadas de El Garcel I indicarían esta tendencia, aunque todas tienen un volumen pequeño: la estructura $30(5058 \pm 364$ hasta 2013$): 423$ l, la estructura 156 (4048 \pm 268 hasta 2013): 7061 y la número 52 (3076 \pm 215 hasta 2013): 995 1. Podrían apuntar en este sentido las excavaciones de las calles Juan II y Leonés (Lorca, Murcia), bajo un estrato datado en $4050 \pm 25 \mathrm{BP}$, con un silo de gran volumen, de $3 \mathrm{~m}$ de profundidad y 4,5 m de diámetro máximo (Pujante 2011).

Finalmente hemos constatado una relación entre forma y volumen. Predomina la forma cilíndrica en ambas mesetas hasta 9001 de volumen (especialmente entre 200 y 400 l) y, a partir de los de 900 l, la forma troncocónica la sustituye.

\subsection{Evidencias de aislamiento de las estructuras ("hoyos")}

El tipo de sustrato es importante para la funcionalidad de las estructuras. Las destinadas al almacenamiento se realizan en lugares altos y secos, en sustratos con un elevado contenido en arcillas y limos ya que resultan ser los terrenos más impermeables (Miret i Mestre 2006).

La superficie de las mesetas de El Garcel está a $30 \mathrm{~m}$ sobre el río, una altura suficiente para evitar las crecidas y la humedad residual. Las estructuras están excavadas en un sustrato de greda o arcilla arenosa. Este material, utilizado principalmente en alfarería y que permite construir formas acampanadas, de menor diámetro en la boca que en el fondo, facilita el cerramiento de las estructuras. L. Siret indicaba el tipo de

\footnotetext{
${ }^{5}$ En El Garcel I el volumen de las estructuras cilíndricas varía en un rango muy amplio, desde 22,09 1 a 3.0151 , llegando incluso a 3.8201 . En las acampanadas va desde 227 a 3.793 1. En El Garcel II, las cilíndricas oscilan entre 28,271 y 1.6081 y las acampanadas entre 66,37 y 2.0371 .
}

sustrato en el que estaban excavadas en su dibujo de la número 108 de El Garcel I (Fig. 8) y P. Acosta (1976) lo describía como "greda dura".

Carecemos en cambio de una descripción o documentación gráfica de la estratigrafía interna de las estructuras, por lo que no podemos deducir su proceso de colmatación/abandono. En las dos estructuras numeradas como 86, L. Siret sólo añade en una nota que había "un poco de relleno reciente" en el fondo. Según P. Acosta (1976) las estructuras tenían un relleno fértil, de tierra vegetal removida por el arado y algunos materiales, que no superaba $\operatorname{los} 30 \mathrm{~cm}$ de potencia.

Además del sustrato adecuado, L. Siret constató el uso de técnicas de aislamiento en algunas de las estructuras: paredes enlucidas con arcilla endurecida con un simple fuego en su interior (Siret 2001: 75). A ellas corresponde el gran fragmento que halló en la estructura acampanada 109 de El Garcel I: "un revestimiento de barro mal cocido" (Siret 2001: lám. 25) (Fig. 8). El grosor del recubrimiento, de 2 a $3 \mathrm{~cm}$ de barro y paja, según las anotaciones de L. Siret, haría posible contener incluso líquidos.

Los restos de arcilla con improntas de cañizo podrían corresponder a estructuras de techumbre o chozas que reducirían el peligro de que entrase agua: “...Probablemente encima de algunos existían chozas hechas con cañizo cubierto de tierra. Algunos fragmentos de esta tierra, endurecida al fuego, tienen las marcas impresas del cañizo y otros las tienen de la madera" (Siret 2001: lám. 25). Fragmentos de adobe con marcas de cañizo hay en las estructuras $n^{\circ} 48,64$ y 171 en El Garcel I, y en la 16 y 48 de El Garcel II. Restos de "barro quemado" en la 141 y 149 de El Garcel I.

P. Flores identificó elementos que podrían estar relacionados con el cerramiento de las estructuras como "piedras llanas" o losas de gran tamaño, generalmente de pizarra. En ocasiones especificaba el peso (en arrobas), entre 6 y $12 \mathrm{~kg}$, lo que implica que su tamaño era suficiente para servir de tapadera (estructuras 2, $110,118,150,159,160$ y 161 de El Garcel I). Un caso similar tendríamos en Terrera Ventura (Tabernas, Almería), donde la estructura 4 (de mediados del III milenio a.C.), de forma acampanada, se cerraba mediante aproximación de hiladas de piedras rematadas con una losa redonda de pizarra (Gusi y Olaria 1991). El derrumbamiento de estas construcciones podría ser la causa de la presencia de piedras en su interior. Martínez y Ponce (1997) han documentado en Lorca (Murcia) el sellado con piedras pequeñas y medianas de este tipo de estructuras interpretadas como silos.

Hay en ambas formas posibles indicios de aislamiento (losas-tapaderas, piedras llanas, barro o adobe con o sin improntas de cañizo). P. Flores señala su presencia en proporciones similares, al menos, en 31 estructuras de ambos tipos. Sin embargo cabe destacar

Trab. Prehist., 75, N. ${ }^{\circ}$ 1, enero-junio 2018, pp. 67-84, ISSN: 0082-5638

https://doi.org/10.3989/tp.2018.12204 


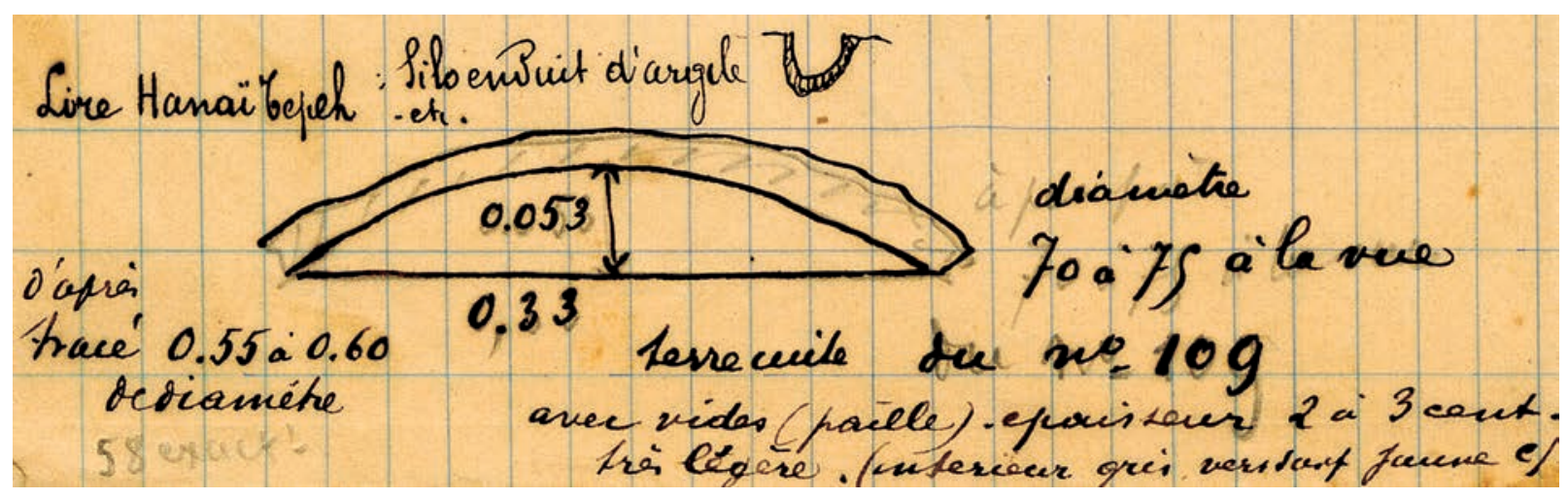

Fig. 8. Detalle del arco de arcilla endurecida al fuego de la estructura no 109 de El Garcel I (Antas, Almería) (dibujo de Luis Siret). Archivo del Museo Arqueológico Nacional, MANF1944_45_FD00746_SEQ_012_P, http://ceres.mcu.es/ (en color en la edición electrónica).

que las evidencias de aislamiento (barro, adobe y piedras llanas) solo aparecen en estructuras entre $400 \mathrm{y}$ 1.8001 , detectándose las losas-tapadera a partir de los 6001 .

Las estructuras "geminadas" que, al cortarse unas a otras, pueden ser permeables si no se aíslan adecuadamente, carecen de evidencias de recubrimientos (o no contamos con información descrita o gráfica al respecto), lo que dificulta su interpretación. No obstante, la presencia en la mayoría de los casos de una gran cantidad de piedras puede relacionarse también con otras funciones según su peso, tamaño, forma y número. En el interior de algunas estructuras (la 21, 45, 52, 54, 58, 96, 141 en El Garcel I), además de piedras planas cuyo tamaño P. Flores no destacaba, había otras que describe como similares a las de molino. Indica la presencia de "piedras llanas", o "X piedras llanas a la forma de molederas" (estructura 103, 153, 176, 178 de El Garcel I; estructuras 21, 24, 25, 34, 42, 43, 45b, 46 de El Garcel II), y "molederas" en ambas mesetas (estructuras 40, 62, 103, 143, 153, 161, 176, 178 de El Garcel I; 1, 4, 5, 6, 9, 13, 14, 16, 18, 19, 21, 25, 31-35, 40, 42-49 de El Garcel II). Su función pudo ser diversa así como el motivo de su presencia en el interior de las estructuras (incluyendo los procesos post-deposicionales). La abundancia de piedras de pequeño y mediano tamaño, muchas de ellas simples guijarros, o molinos fracturados, es frecuente en yacimientos con estructuras en negativo (Márquez Romero y Jiménez Jáimez 2010).

Consideramos que en ocasiones las piedras contenidas en los silos pudieron servir, dispuestas en el fondo, como aislantes o para el apoyo de vasijas (de fondo cónico o cóncavo), como las 2.000 piedras de pequeño tamaño de la estructura 47. Ahora bien, según P. Flores, aparecían en casi todas las estructuras de ambas mesetas aunque no en tan alto número.
Otra posibilidad que nos sugiere la abundancia de piedras de molino es que las estructuras se destinaran a almacenar materias primas o útiles. Las molederas pudieron ser reservadas allí a la espera de su utilización para la molienda, triturado de ocre o cualquier otro uso secundario (como enlosado, apoyo para vasijas, material de construcción). No hay una relación significativa entre la forma de las estructuras y la presencia de piedras de molino: están presentes en todo tipo de formas y tamaños.

En otros casos quizá estemos ante piezas líticas en proceso de elaboración, como la "piedra trabajada" (estructuras 49, 56, 91 y 94 de El Garcel I y la 16 de El Garcel II) y los fragmentos de mármol (estructuras 158 y 160 de El Garcel I), posiblemente destinados a ser brazaletes.

\subsection{Propuesta de uso o función}

Hemos tenido en cuenta los datos referidos a las estructuras de El Garcel (Antas, Almería) y a los materiales que contenían para proponer su posible uso. La complejidad para interpretar las estructuras excavadas ha sido ampliamente reconocida, por la multifuncionalidad, reutilización y reciclado de las mismas. Esta situación se da incluso cuando se han llevado a cabo recientes excavaciones y se han obtenido fechas absolutas (Aranda et al. 2016).

Las medidas de los hoyos de ambas mesetas no son propias de fondos de cabaña: el mayor diámetro conocido tiene $2 \mathrm{~m}$ en la base y en la boca, con $50 \mathrm{~cm}$ de profundidad ( ${ }^{\circ} 150$ de El Garcel I). En yacimientos recientemente excavados, como Valencina de la Concepción (Sevilla), hay estructuras de similares dimensiones como la CUE39 cuyo uso "residencial" se pone en duda, e incluso otras de mayor tamaño, polilobuladas y con abundantes adobes con improntas 
vegetales y marcas de enlucido, que se consideran simplemente "polifuncionales" (Fernández Gómez 2013: 147; Sardá Piñero 2013: 154). Se insiste en la necesidad del debate sobre las "colmataciones-deposiciones deliberadas frente al concepto clásico de basureros", y en la dificultad de inferir su uso primigenio (Sardá Piñero 2013: 156).

En yacimientos próximos como el de Caravaca (Murcia), las estructuras consideradas "fondos de cabaña" alcanzan al menos un diámetro entre 6 y $10 \mathrm{~m}$ (y una profundidad entre 30 y $40 \mathrm{~cm}$ ). En Marroquíes Bajos (Jaén) cuentan con más de $3 \mathrm{~m}$ de diámetro y en su interior tienen estructuras de transformación y consumo, e incluso silos internos (Lizcano et al. 2005) constituyendo un hábitat casi troglodítico al tener más de $2 \mathrm{~m}$ de profundidad.

No obstante, según L. Siret (2001), algunos "silos" debieron estar bajo "chozas" a tenor de los restos recuperados de barro con improntas de cañas. P. Acosta (1976: 190) relacionaba los "fondos de cabaña" que identificó "con una posible función de hogar o de silo", y señalaba la presencia de "series de agujeros de $20 \mathrm{~cm}$ de diámetro y $15 \mathrm{~cm}$ de profundidad". Estas últimas estructuras debieron ser hoyos de poste, dado su tamaño y la ausencia de materiales en su interior (como ocurre en los hoyos 1a, 60b, $71 \mathrm{~b}$ y tal vez $59 \mathrm{~b}$ en El Garcel I). Así pues, también en este caso parece más probable que se trate de simples estructuras cubiertas por un entramado vegetal soportado por unos postes.

Los diámetros (40 $\mathrm{cm}$ de diámetro y entre $50 \mathrm{y}$ $65 \mathrm{~cm}$ de profundidad) de las número 12, 38 y 49 de El Garcel II superan los normales para un hoyo de poste (unos $20 \mathrm{~cm}$ de diámetro) y, además, contenían materiales. En Terrera Ventura (Tabernas, Almería), hoyos con similares dimensiones fueron interpretados como estructuras para contener agua (Gusi y Olaria 1991). En la Jordania actual sirven para conservar frutas y leguminosas (Miret i Mestre 2006).

Otras estructuras pudieron tener una función de hogar, si bien las evidencias no son del todo suficientes. Para considerar el uso de una estructura como hogar, fosa-hogar o fosa-horno, hemos de tener en cuenta, además del tamaño (estructuras en torno a los $20 \mathrm{~cm}$ de profundidad y los $70 \mathrm{~cm}$ de diámetro para los hogares, o mayores medidas para una fosa-horno), la presencia de indicadores de combustión como los "huesos de oliva calcinados" en la estructura 23a o 23b de El Garcel I (P. Flores no deja claro en el diario en cuál apareció), o los "pedacitos de carbón" en las estructuras 28 y 147 de El Garcel I y en la 34 de El Garcel II. Sin embargo su deposición pudo ser secundaria. En El Garcel I sólo las estructuras 141 y 149 , las de mayor diámetro (100 y $130 \mathrm{~cm})$ y profundidad $(100 \mathrm{y} 40 \mathrm{~cm})$ con barro quemado sufrieron un proceso de calentamiento. Pero estos datos no son concluyentes ya que también puede ser resultado de una posible desinfección y endurecimiento de la fosa para uso de almacenamiento.

Siguiendo con el análisis sobre posibles funciones de las estructuras, no hay evidencias de que sean fosas de enterramiento. En El Garcel I, sin asignar a hoyos, apareció un fragmento de falange humana conservada entre los restos de fauna y P. Flores solo halló un cráneo probablemente femenino ${ }^{6}$ en el interior del 108: una estructura acampanada, con dos fondos a distinta profundidad (Fig. 8). P. Flores informó a L. Siret de su hallazgo por carta, por lo que en este caso no hay referencia en el cuaderno. Para el autor, se trataba de "sin duda un accidente, pues nada permite considerar que fueran sepulturas" (Siret 2001: 75 y lám. 25). En nuestra opinión, el cráneo humano debió ser depositado intencionadamente, como se ha constatado en otros yacimientos peninsulares. De esta estructura se conserva además una valva de Glycymeris perforada.

Un paralelo próximo lo encontramos en el enterramiento secundario de Caravaca (Murcia) (tipo $\mathrm{C} 1 \mathrm{de}$ Caravaca, U.E. 1018) que se atribuye a un horizonte campaniforme en la fase final del poblado (Pujante 1999). En el área central de la península se vienen documentando casos similares desde los hallazgos madrileños de El Negralejo en un horizonte Cogotas I (Blasco et al. 1983). En fechas recientes se han recuperado cráneos aislados en El Molino de Huelves (Cuenca) en un horizonte Calcolítico (Chautón 2010) o en el Cerro del Cuquillo en Villaluenga de la Sagra (Toledo) donde, en una estructura de similares características a la 108 de El Garcel, se localizó un cráneo, también femenino, aislado y datado en un Bronce Antiguo (Torija et al. 2010).

Las dimensiones y formas de las estructuras tampoco desvelan, en general, la existencia de pozos (Fernández Gómez 2013) o zanjas como las relacionadas en Valencina de la Concepción (Sevilla) con la preparación de compost (Bernáldez et al. 2013).

En definitiva, interpretamos la mayoría de las fosas como silos de almacenamiento, posiblemente de productos variados (cereales, leguminosas, frutos secos, materia prima lítica), algunos de los cuales, al menos, fueron reutilizados en distintos momentos. Su variabilidad formal podía estar relacionada con el producto almacenado (Miret y Mestre 2006) o con la temporalidad de su uso: los troncocónicos o matraces para almacenar grano a largo plazo, los cilíndricos para almacenar frutos secos o introducir en ellos vasijas de almacenamiento, y/o para una temporalidad más corta

\footnotetext{
${ }^{6}$ El estado de conservación es muy deficiente pero han podido determinarse fragmentos de parietal, temporal, occipital, 4 dientes y una apófisis mastoide derecha en buen estado, lo que permite proponer también que tuviera unos 15 años de edad (María Molina, com. pers.).
} 
(cualquier producto, incluso líquido). Los cilíndricos más pequeños (en torno a $80 \mathrm{~cm}$ de diámetro y menos de $1 \mathrm{~m}$ de profundidad) pudieron servir para almacenar forraje (Bernáldez et al. 2013).

En principio consideramos que las estructuras geminadas que interseccionan sus volúmenes no son contemporáneas, y que tal disposición se debe a una estratigrafía horizontal. Sin embargo a falta de dataciones absolutas que lo contrasten, tampoco descartamos que pudieran ser hoyos "comunicantes" con una función o uso por determinar (Fig. 4A).

\section{LOS MATERIALES}

No podemos analizar en profundidad los materiales en este estudio pero sí hacer algunas consideraciones de conjunto necesarias para la valoración de las estructuras. Partimos de la colección conservada en el MAN aunque se han consultado otros fondos (Deramaix 1992; http://www.britishmuseum.org/research/collection online/collection_object_details.aspx? objectId= 1392322\&partId=1 (consulta 2-12-2015), http://ceres. mcu.es). Para aproximarnos al contexto excavado, hacemos una "estimación mínima" de los datos de P. Flores cuando estos no son numéricos, estimación más fiable cuanto menor sea el número original. Según esos datos, de las excavaciones procederían unas 4.700 piezas, de las que se conservan 1.075. Ya se indicó que la mayor discrepancia se observa entre los materiales localizados en las estructuras y los que no tienen esa referencia, que son muy superiores en El Garcel I. Valoramos la posibilidad de un cambio de metodología en la excavación de cada meseta, pero no hemos podido constatar este aspecto.

\subsection{Grupos de materiales}

\subsubsection{La cerámica}

La cerámica puede considerarse muy escasa: 83 restos en total de los que sólo contamos hoy con 33 . Aparece en 50 estructuras (47 según P. Flores), que son sólo el $20 \%$ del total, y pocas de ellas tienen más de un elemento (Tab. 4). La mayoría corresponden a recipientes completos (o casi) o a fragmentos significativos (decorados, con asas,...), por lo que pudo haber una recogida sesgada. Sin embargo P. Flores indica valores sólo ligeramente más altos $\mathrm{y}$, además, los restos son los mismos que comenta L. Siret.

La descripción de P. Acosta (1976) es muy similar al conjunto estudiado en el MAN. Acabados, pastas, tamaños y formas corresponden a recipientes de cocina y de almacenaje, en su mayoría asimilables al concepto de "tinaja" (vasija de almacenamiento de tamaño mediano/grande). Destacamos la presencia de mamelones de lengüeta de gran tamaño (próximos a $l o s \quad 10 \mathrm{~cm}$ ), así como un asa multiforada y otra tipo pitorro, que indican una fase antigua del yacimiento.

Resulta significativo un pequeño conjunto de fusayolas irregulares diseminadas por ambas mesetas, únicas evidencias de una actividad no necesariamente textil. Por último, la copa tienen una forma que no se corresponde con los estándares argáricos (de hecho su datación es posterior a esa fase: $4048 \pm 268,2013$ TL). La ponemos en relación (al igual que el cráneo) con algún componente ceremonial de amortización.

Consideramos que el conjunto cerámico de El Garcel puede entenderse en un contexto de almacenamiento y consumo puntual, como podría ser el propio de un espacio usado de modo esporádico, es decir, más como lugar de trabajo que de hábitat permanente.

\begin{tabular}{|c|c|c|c|c|}
\hline & Forma & $\begin{array}{c}\text { GI + } \\
\text { GII }\end{array}$ & $\begin{array}{c}\text { GI } \\
\text { No Ref. }\end{array}$ & $\begin{array}{l}\text { No } \\
\text { Ref. }\end{array}$ \\
\hline \multirow{8}{*}{ 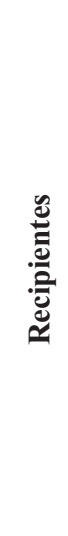 } & Tinajas & 8 & 2 & 33 \\
\hline & Ollas / Orzas & 9 & 2 & 36 \\
\hline & Botelliformes & 2 & & 3 \\
\hline & Cazuela & & & 5 \\
\hline & Otras formas & 1 & 1 & 1 \\
\hline & Pequeños recipientes & 2 & & \\
\hline & Cuencos & & 1 & 4 \\
\hline & Indeterminados & & & 5 \\
\hline \multirow{4}{*}{$\frac{\tilde{0}}{\frac{0}{0}}$} & Fusayolas & 10 & 7 & \\
\hline & Crecientes & 1 & & 4 \\
\hline & Pesa de telar & & & $1 ?$ \\
\hline & Ficha & & & 1 \\
\hline Tota & 139 & 33 & 13 & 93 \\
\hline
\end{tabular}

Tab. 4. Formas cerámicas identificadas del yacimiento de El Garcel (Antas, Almería) en la colección Siret del Museo Arqueológico Nacional. Los valores corresponden a una estimación del número mínimo de objetos a partir de los fragmentos conservados. Los tipos obedecen a criterios de tamaño y a relaciones de proporción y apertura, no a una identificación funcional directa. GI+GII: número de elementos hallados en estructuras del El Garcel I y El Garcel II; GI No Ref.: número de elementos hallados en El Garcel I, sin referencia a número de estructura; No Ref.: Elementos procedentes de El Garcel sin referencia a estructura ni a meseta. 


\subsubsection{Piedra tallada}

L. Siret otorga mayor interés a la piedra tallada que a otros conjuntos. Un motivo puede ser su abundancia: el $86 \%$ de los hoyos contenían elementos de sílex y/o cuarzo y el yacimiento ha proporcionado más de 17.000 piezas en total.

Ya se ha comentado que las diferencias observadas en la distribución de los materiales con y sin contexto entre ambas mesetas, nos hacen sospechar un cambio de criterio en la excavación. Por otro lado, la materia empleada como soporte es en su mayoría de buena calidad destacando el llamado sílex melado. Mientras en El Garcel I sólo hemos podido documentar el trabajo del sílex, en El Garcel II encontramos además cuarzo, caliza, cuarcita y un núcleo pequeño en cristal de roca. Siendo menor el número de estructuras registradas en El Garcel II, la presencia de material lítico es mucho mayor en esta meseta, si bien se trata en su mayoría de piezas sin retocar. En conjunto destaca el número de trapecios y el mayor porcentaje de geométricos en El Garcel I (44 frente a 7). Si a estos datos sumamos la presencia de muescas, así como de 18 truncaturas (sólo una de ellas de Garcel II) y microburiles que podrían relacionarse con la extracción de trapecios, vemos aún más desequilibrada la distribución. Destacan así mismo los núcleos prismáticos para la extracción de hojitas, así como la presencia de estas, ofreciendo un conjunto caracterizado por su pequeño tamaño (Fig. 9).

No hemos podido reconstruir el mapa de localización de cada una de las estructuras del yacimiento, pero la distribución del material lítico no parece formar concentraciones, por lo que consideramos que no todo el material comentado entró a formar parte de los hoyos durante un proceso de limpieza.

El predominio de geométricos y microburiles coincide en otros yacimientos con las primeras presencias cerámicas, si bien los trapecios se documentan esencialmente en los niveles mesolíticos, siendo su hallazgo en niveles con cerámica muy inferior a la de triángulos y segmentos. En El Garcel las características de los trapecios conservados difieren de otros conjuntos (Cacho et al. 1995; García Puchol 2006). En este caso la forma dominante es el trapecio isósceles y no se aprecia el retoque de doble bisel. En La Peña de la Abuela (Ambrona, Soria) y en el Túmulo de la Sima (Miño de Medina, Soria) hay también un predominio claro del retoque abrupto, tamaños pequeños y aparición de microburiles en contextos del IV milenio (Alegre 2005).

En conjunto estamos ante industrias de carácter microlítico y arcaizante, cuyo referente podría estar en un Neolítico Final acorde con la primera fecha de ocupación de El Garcel.

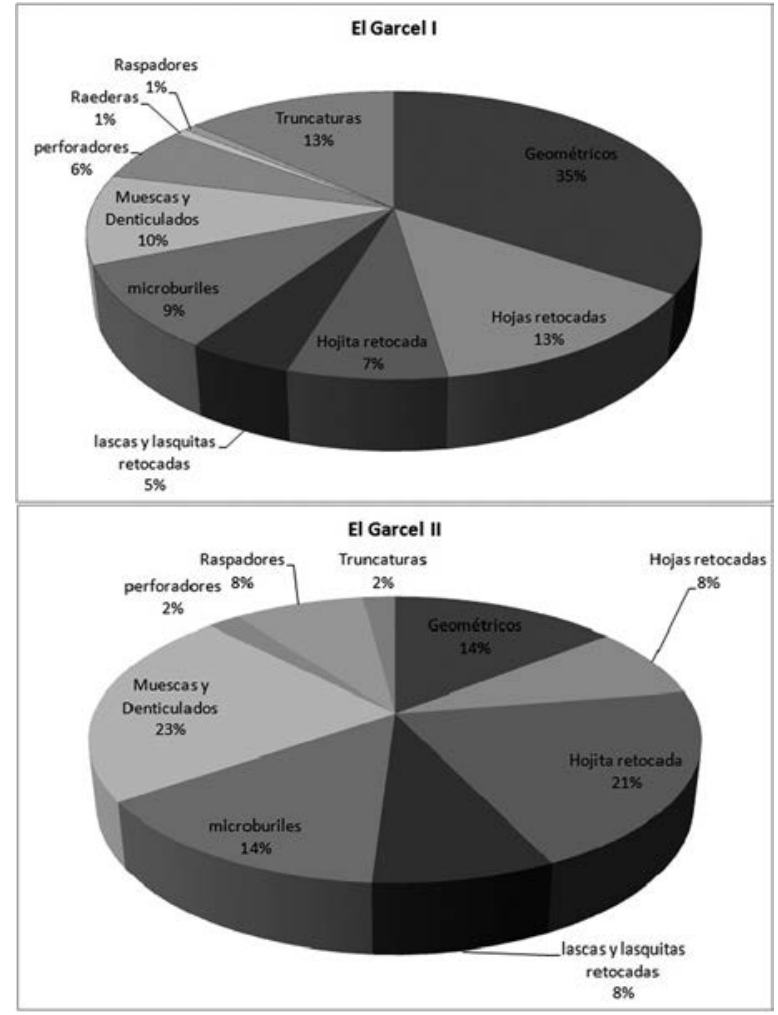

Fig. 9. Distribución de la industria lítica en El Garcel I y El Garcel II (Antas, Almería).

\subsubsection{Piedra pulida}

Gracias a la combinación de los datos de P. Flores con los materiales conservados en el MAN, sabemos que se recuperaron objetos de piedra pulida en 166 hoyos. A diferencia del caso cerámico, lo más frecuente es que cada hoyo contuviera más de uno. La suma de las piezas de piedra pulida con y sin contexto supera las 800 piezas. La materia prima identificada corresponde a micaesquistos, mármol, arenisca, fibrolita y diorita.

En conjunto podemos hablar de una elevada fracturación y reutilización de los objetos (hachas, azuelas, cinceles...). Destacamos los que hemos llamado "bastoncillos de esquisto" que hemos podido reconocer en otros yacimientos de la zona como Almizaraque. Los tamaños y formas son variables y superan el centenar entre el material no asignable a hoyos (Tab. 5). Pensamos que al menos en algunos casos estos "bastoncillos" han podido usarse como retocadores y alisadores.

Los elementos de adorno son muy escasos. Contamos con una docena de fragmentos de brazalete de mármol, así como otro mayor abandonado tal vez en el proceso de elaboración. Más llamativa es la escasez de cuentas de collar, reducida a una gran cuenta de 


\begin{tabular}{|l|l|c|c|c|}
\hline $\begin{array}{c}\text { Piedra } \\
\text { pulida }\end{array}$ & \multicolumn{1}{|c|}{ Tipo } & Ref. & $\begin{array}{c}\text { No } \\
\text { Ref. }\end{array}$ & $\begin{array}{c}\text { Sub- } \\
\text { totales }\end{array}$ \\
\hline \multirow{2}{*}{ Útiles } & $\begin{array}{l}\text { Hachas y } \\
\text { cinceles (frag.) }\end{array}$ & 44 & 141 & 185 \\
\cline { 2 - 5 } & Molederas & 10 & 4 & 14 \\
\cline { 2 - 5 } & Otros & 46 & 588 & 634 \\
\hline \multirow{2}{*}{ Adornos } & Brazaletes & 4 & 9 & 13 \\
\cline { 2 - 5 } & Cuentas & 1 & 4 & 5 \\
\hline Total & & 105 & 746 & $\mathbf{8 5 1}$ \\
\hline
\end{tabular}

Tab. 5. Objetos de piedra pulida identificados en el Museo Arqueológico Nacional. Ref: con referencia a número de estructura; No Ref: sin referencia a número de estructura.

variscita (3 $\mathrm{cm}$ de longitud máxima) de la estructura GI/145 y otras cuatro sin referencia.

Según la documentación, faltan en particular las molederas. Si hacemos una estimación de las cifras que proporciona $\mathrm{P}$. Flores, entre ambas mesetas habría más de 300 . No debió recoger más que una pequeña muestra debido a su peso y volumen. En la muestra conservada destacan las molederas pasivas de micaesquisto con cazoleta para ocre. Esto resulta especialmente interesante si tenemos en cuenta que en El Garcel se conservan machacadores con restos de ocre y un elevado número de fragmentos de este mineral, todos muy pequeños y con fuertes abrasiones, lo que parece indicar un intento de agotar la materia.

Otras piezas de obligada mención son los llamados "ídolos tipo Garcel". Se trata de cantos rodados con dos escotaduras en línea que pudieron usarse como pesas, y placas de micaesquisto que, por los restos conservados, pudieron ser machacadores de ocre.

\subsubsection{Metales}

L. Siret atribuía la presencia de escorias y cobre en este yacimiento a una "civilización más reciente", y no a la primera que vivió allí (Siret y Siret 1890: 9). Según P. Acosta los indicios metálicos procedían del espigón occidental (suponemos que de El Garcel I), pero según nuestros datos, hay presencia metálica en ambas mesetas.

El único objeto elaborado es un punzón, sin más referencia que su pertenencia a este yacimiento y cuya composición (cobre ligeramente arsenicado) es coherente con un conjunto calcolítico (Montero 1994; Rovira y Gómez 1994). Al primer estudio de 7 fragmentos de mineral de cobre habría que sumar 2 fragmentos de escorias, sin referencia de estructura ni de meseta, localizados en esta revisión del yacimiento.

Se han localizado indicios de metal en los hoyos 14, 34 y 35 de El Garcel II. En los dos primeros detectamos láminas de sílex con adherencias. Al tercero pertenece un fragmento de escoria siglada por L. Siret, cuya composición es propia de fases avanzadas. En las láminas de sílex es difícil precisar si las adherencias corresponden al contacto con un elemento mineral natural o con metal elaborado?

De este modo, podemos afirmar que la presencia metálica en este yacimiento es muy limitada pero no extraña dadas las dataciones de su prolongada ocupación y el contexto de hallazgo, lo que se adecua al uso del lugar de tipo discontinuo y temporal.

\subsubsection{Industria ósea}

No se aprecian diferencias significativas entre El Garcel I y II. Hay algún elemento de industria ósea en 74 estructuras y, según los datos de P. Flores, en origen serían pocas más (133 piezas). La mayoría son valvas perforadas por la abrasión marina. La única pieza que denota un trabajo más esmerado es un colgante sobre costilla (Maicas 2007: 178).

\subsubsection{Fauna}

Los restos de fauna debieron superar los 2.000 fragmentos, documentados en 191 hoyos, pero hoy no conservamos más que 64, en su mayoría malacológicos. A ellos podemos añadir 88 restos de mamíferos y 328 de malacofauna en El Garcel I, sin referencia a hoyos, y 27 restos de malacofauna en El Garcel II. Los restos más abundantes corresponden a cientos de gasterópodos terrestres que según P. Flores serían aún mucho más numerosos. Los restos de mamíferos corresponden a porciones anatómicas y taxones variados: ovicápridos, suidos, grandes bóvidos, cérvidos y lagomorfos. La fauna está sobrerrepresentada por la gran cantidad de caracoles terrestres, cuya incorporación al registro sospechamos muy posterior a la ocupación del yacimiento. Si exceptuamos este taxón, la escasez de fauna es la tónica dominante, lo que se ha observado también en otros yacimientos de estas características (Blasco et al. 2016).

\footnotetext{
${ }^{7}$ El análisis de las adherencias de la lámina recuperada en el hoyo 34 podría indicar lo segundo (Ignacio Montero com. pers.).
} 


\subsection{Relación entre el volumen de las estructuras y los elementos muebles que contienen}

Se pueden observar tres tendencias levemente distintas en la cuantificación de los elementos (Fig. 10). Un primer bloque corresponde a los materiales más numerosos: los líticos y la fauna que aparecen entre el 80 y el $100 \%$ de los hoyos de tamaños superiores a 600 1. La piedra tallada se distribuye prácticamente por igual a partir de las estructuras de $900 \mathrm{l}$. Eso no ocurre con la cantidad de piedra pulida que aumenta en función del volumen.

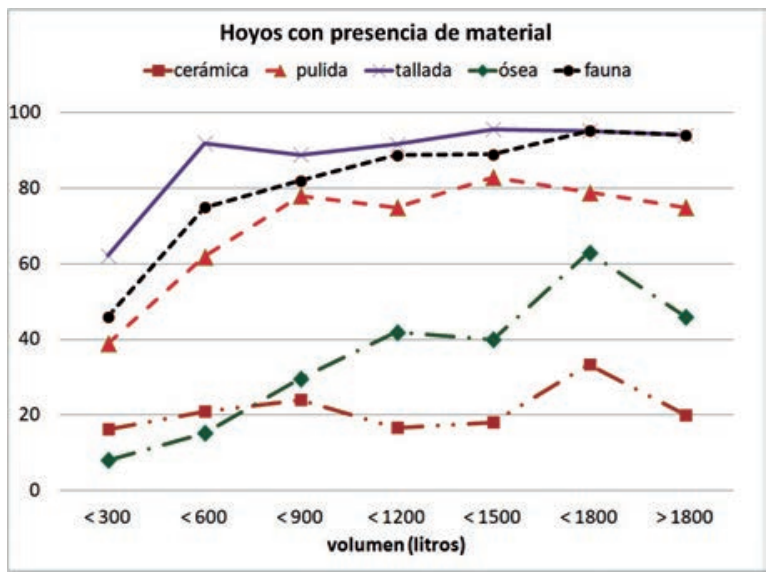

Fig. 10. Porcentaje de estructuras El Garcel I y El Garcel II (Antas, Almería) con materiales según la distribución de intervalos de volumen (en color en la edición electrónica).

Los grupos de materiales menos abundantes son la industria ósea y la cerámica. Se reparten de forma homogénea entre las estructuras, independientemente de su volumen: entre 1 y 2 fragmentos por hoyo. Al margen de esta generalidad, se observa que la industria ósea crece de forma casi lineal mientras que la cerámica mantiene una presencia escasa y estable en todo el conjunto con independencia del volumen de la estructura. En ambos casos los valores más altos se concentran en las estructuras de 1.8001 y no en las de mayor tamaño, lo que podría estar relacionado con un proceso diferente de colmatación. Las cifras del resto de ítems son tan bajas que no pueden ser valoradas.

Esta distribución de materiales en las estructuras no nos permite apreciar usos específicos. El material sin y con asignación a hoyos es muy similar. Ello nos inclina a pensar que su distribución entre las distintas estructuras debe obedecer a tareas de limpieza y colmatación posteriores al uso primario. No obstante podrían vincularse con dicho uso algunos materiales, como las cerámicas.
Para afianzar cualquier hipótesis sería necesario conocer la estratigrafía de estas estructuras. Sabemos que algunas cerámicas sirvieron como contenedores en el interior de los silos, donde P. Flores las documenta de pie. En ocasiones fueron reutilizadas como contenedores incluso tras su fractura. En conjunto consideramos significativo que, en un yacimiento "postpaleolítico", la proporción entre el material lítico y el cerámico esté tan desequilibrada a favor del primero, algo que podría acentuarse todavía más si atendiésemos al volumen global de materiales no adscritos a estructuras. De un total de casi 20.000 piezas, la cerámica no llega a 150. Así pues, creemos que estamos, cuando menos, ante un conjunto arcaizante, consideración sobre la que volveremos en el último apartado.

\section{CONCLUSIONES Y VALORACIÓN}

El Garcel es un "campo de hoyos" ubicado en dos mesetas contiguas que configuran un único yacimiento. En su gran mayoría, estas "estructuras negativas" desempeñaron una función de almacenamiento a media escala por su tamaño, forma y evidencias de aislamiento frente a la humedad y biodeterioro. Corresponden a un periodo muy amplio de tiempo, al menos desde finales del IV milenio a finales del II milenio a.C. Las tres nuevas fechas de TL han contribuido a afianzar nuestra sospecha, basada en la tipología de los materiales conservados, de una larga duración del uso de sus dos emplazamientos.

No hemos apreciado diferencias significativas entre ambas mesetas. Carecemos de fechas suficientes y en especial nos faltan para El Garcel II, pero tanto las estructuras como los materiales que contienen presentan unas características y cantidades similares. Esta consideración pudo motivar también a L. Siret a valorarlo en conjunto, sin distinciones.

La tipología de los conjuntos líticos y cerámicos (trapecios, brazaletes de mármol, asas multiforadas, pitorros...) nos indica además un panorama "arcaizante" que define un primer momento de ocupación más amplio que los sucesivos. Un mayor número de dataciones enriquecería el conocimiento sobre este controvertido yacimiento, precisando su grado de continuidad/abandono, la simultaneidad o no en el uso de ambas mesetas o la contrastación del incremento en el volumen de las estructuras con el avance del tiempo.

Consideramos que estos "campos de silos" son el resultado final de motivaciones distintas a las de los "recintos de fosos" de la Península Ibérica con los que conviven desde los últimos siglos del IV milenio a.C. en la Meseta y Cuenca del Guadiana hasta los primeros siglos del II milenio a.C. en el valle del Guadalquivir (Aranda et al. 2016). Estos recintos cuentan con es- 
tructuras de almacenamiento pero también con muchos otros tipos de estructuras, que evidencian que estamos ante lugares de habitación con mayor variedad de actividades en el mismo emplazamiento, aunque sea difícil estimar (a pesar de las dataciones absolutas) el grado de permanencia y continuidad en los mismos (Aranda et al. 2016). Están además en otro tipo de localización, altura relativa y entorno.

Así mismo, El Garcel carece de fosos y muros perimetrales, por lo que no estamos ante un lugar que materializara un posible sentimiento de "identidad", de "agregación interna" (Díaz-del-Río 2013; Márquez Romero 2013) o, por el contrario, de exclusión a los externos a esa comunidad, una intención defensiva o protectora del producto/excedente allí acumulado.

La localización del yacimiento de El Garcel en mesetas de greda o margas terciarias, viene siendo una elección recurrente ya que el tipo de sustrato era fundamental para la finalidad de estas estructuras, como también lo era la ubicación a cierta altura sobre el cauce fluvial, evitando las consecuencias de sus crecidas, muy probables en el sureste peninsular debido al régimen torrencial de lluvias y ríos. También se valoraría su cercanía a los campos de cultivo y a los lugares de asentamiento, de los que faltaría investigar cuáles pudieron ser para los momentos más antiguos, así como su contemporaneidad y relación con La Gerundia y El Argar, muy cercanos a El Garcel.

Consideramos que la escasa potencia estratigráfica puede deberse sólo en parte a las labores agrícolas practicadas en el lugar hasta los años 60. La escasez de cerámica y de fauna, así como la elevada fracturación de los materiales presentes, es común a yacimientos de este tipo y a ello hay que sumar la dificultad para identificar verdaderas cabañas (pequeño diámetro, escasez de hoyos de poste y hogares). Todo ello nos inclina a considerar que estamos ante un uso semipermanente o temporal de ambos emplazamientos, donde se llevaban a cabo distintas actividades.

La homogeneidad de los materiales en ambas mesetas, a lo largo de dos milenios, indica una continuidad en las técnicas de producción allí practicadas, no sólo en la elaboración de útiles, sino también en la construcción de las estructuras, lo que muestra que tales técnicas eran eficaces y suficientes para las actividades allí desarrolladas.

Posiblemente la actividad mejor contrastada sea el almacenamiento de productos vegetales (y, por el aislamiento, incluso agua), bien de forma directa o bien en el interior de vasijas. Las "tinajas" se utilizaron (al menos en parte) para preservar mejor determinados productos, preferentemente sólidos como olivas y uvaspasas o para separarlos dentro del silo de otros como los cereales, así constatados por los restos de "trigo y centeno carbonizados" (Siret 2001: 85).
Menos claro es el "almacenamiento" de materias primas (nódulos, bloques de mármol), herramientas (percutores, molinos) y útiles a medio elaborar o ya terminados en diferentes materias (sílex, cuarzo, fibrolita, esquisto; cerámica, hueso y concha). Debido a la carencia de datos relacionados con la colmatación de las estructuras, no podemos indicar si los elementos hallados fueron depositados intencionalmente en los hoyos, o llegaron a ellos accidentalmente desde la superficie. Sin embargo, su presencia tanto atrapados en los hoyos como fuera de los mismos, nos permiten proponer la práctica de otras actividades en el yacimiento como la talla lítica (de sílex y cuarzo) y la molienda de colorante.

De esta segunda actividad tenemos representados todos los elementos de la cadena de producción (molederas con restos de ocre, machacadores, conchas con restos de mineral y múltiples fragmentos de colorante), sin que excluyamos su uso para la molienda de otros recursos, como se ha podido comprobar en La Loma de Illora (Aranda et al. 2012). Si aceptamos el alto número de molederas que describe P. Flores, podríamos considerar que, dado su peso, permanecerían en las mesetas transportándose desde ellas sólo el producto elaborado, la harina o el polvo de ocre. Es decir, en ambas mesetas se practicaría también todo o parte del procesado de los cereales.

Por lo que respecta a la piedra pulida, hachas, azuelas y cinceles muestran el mayor grado de fracturación, lo que parece indicar un uso intenso en la propia meseta, quizás relacionada con la construcción de las estructuras o el procesado de los recursos, ya que no tendría sentido transportar piezas rotas para desecharlas allí.

Las cifras de cerámica son sorprendentemente bajas, máxime dada su amplitud cronológica, lo que nos reafirma en que no estamos ante un lugar de asentamiento permanente. En su mayoría parecen estar ligadas al almacenamiento y apenas hay cerámica de cocina. A esta propuesta contribuye la escasez de restos de fauna, y la ya mencionada circunstancia de no haber claras estructuras de habitación.

Otras actividades plantean mayores dudas. Los datos sobre metalurgia son confusos y escasos. El volumen de restos recuperados y sus características no permiten pensar más que en hechos aislados. El Garcel sería, pues, un espacio destinado principalmente al almacenamiento y a la práctica de un pequeño número de actividades. Dado el amplio marco cronológico que se propone y la escasa implantación sobre el terreno, sin evidencias claras de estructuras de habitación, esas actividades se realizarían durante periodos breves pero de forma recurrente.

La presencia de un cráneo humano aislado en una de las estructuras "re-excavadas" y "recicladas" (número 108 de El Garcel I) indica un acto intencionado, nada 
casual, consecuencia de una práctica social extendida, constatada en otros contextos similares de yacimientos del sur peninsular. Su difícil interpretación, por lo exiguo de su contexto y de la información, ha sido atribuida a prácticas relacionadas con la legitimación de la ocupación de un territorio (Lizcano et al. 2005) mediante el recuerdo a los antepasados (Rubio 2004). Algo similar podría decirse de la presencia de una copa en una de las estructuras. Como ha sido indicado en general para los recintos de fosos, y en particular para Marroquíes Bajos (Jaén), las prácticas sociales relacionadas con estrategias identitarias se mezclan con la función práctica de las estructuras (Aranda et al. 2016). Pero una aproximación a estos casos, a su problemática, así como el estudio más detenido de los elementos muebles, excedería los límites y los objetivos del presente trabajo.

Los escasos datos sobre la estratigrafía interior de las estructuras, no ofrecen la oportunidad de inferir su grado de reutilización. En general consideramos que estuvieron poco tiempo abiertas y sufrieron una rápida colmatación ya que la mayoría conservan bastante bien su forma. Sin embargo, recientes trabajos experimentales muestran que un silo se puede reutilizar si su estructura se mantiene regularmente mediante un fuego, que evita que sus paredes se derrumben (Reynolds 1998; Ollich et al. 2012; Cardona et al. 2013). El problema es que estos estudios son relativamente recientes y que aún no pueden indicar las evidencias, en su caso, de cuántas veces han podido ser reutilizados y durante cuanto tiempo.

Una vez terminado su uso habitual, se producía su abandono o su reciclaje, principalmente como basurero, rellenándose con la tierra de la superficie que incluiría los materiales presentes en ella, lógicamente posteriores a las fechas de su uso inicial.

Las dataciones absolutas de El Garcel (Antas, Almería) muestran que el sistema de almacenamiento en silos se practicó al menos entre finales del IV y finales del II milenio a.C. Si bien durante el IV y III fue más frecuente que en el II milenio a.C. (Márquez Romero y Jiménez Jáimez 2010), es interesante tener en cuenta dicha práctica, y sus implicaciones socio-económicas, para el período convencional de la Edad del Bronce del sur de la Península Ibérica, y no atribuirlos a priori a los períodos previos.

En el centro peninsular, las ocupaciones se superponen a lo largo de toda la Prehistoria Reciente repitiendo los mismos enclaves que inicialmente fueron elegidos por los grupos neolíticos. Las cronologías absolutas de los yacimientos madrileños arrojan largas perduraciones de estos sistemas de almacenamiento, arrancando en el paso del VII al VI milenio BP (Blasco et al. 2016: tab. 1), para continuar siendo frecuentes hasta finales de la Edad del Bronce como también se observa en la zona del Guadiana occidental (Duque et al 2009). En el noreste peninsular, este tipo de almacenamiento perduró hasta el I milenio a.C., cuando quedó obsoleto el sistema al consolidarse una economía integrada en el nuevo marco de la organización política estatal romana (Salido Domínguez 2009).

Las estructuras que hemos considerado mayoritariamente como silos son pequeñas en su mayoría. Son aptas para usarse por unidades domésticas como un almacén, que garantizase la cantidad suficiente de alimento, pequeños intercambios o la siembra del siguiente año. Sin embargo, durante aproximadamente dos mil años, el número de estructuras debió variar. Es muy posible que El Garcel sufriera períodos de abandono, así como variaciones en el número de individuos que se sirvieran de las mismas.

Por otra parte, no sólo habría que tener en cuenta el número de fosas y su volumen (la cuantificación), sino quién o quiénes dispondrían de su beneficio, cómo sería la apropiación, distribución y disfrute de lo almacenado (Vicent 1991; Gilman 1997). Durante ese largo período de utilización, no sólo debió variar el número de estructuras sino también el uso social de las mismas, pasando por distintos procesos de apropiación y redistribución de los productos. Lo que pudo ser una actividad de almacenamiento de una pequeña comunidad, autosuficiente, también pudo ser un lugar de almacenamiento de excedente, con apropiación desigual del mismo.

Lógicamente yacimientos del tipo "Garcel" no nos van a dar respuesta sobre la organización socio-política y económica de los grupos sociales de la llamada Prehistoria Reciente. Sin embargo, forman una parte importante de un contexto más amplio que conjuga la información de los lugares de habitación, de enterramiento y de otras actividades. Es imprescindible su análisis en ese intervalo cronológico en el que el sureste peninsular se sometía, con distintos ritmos y diferentes sociedades, a los profundos cambios conducentes de manera generalizada hacia la "complejidad social" (Chapman 1991). Este proceso no tuvo que ser necesariamente lineal ni similar en todas partes. El Garcel formó parte de esta evolución. Pretendemos haber contribuido con su estudio a despertar el interés por el papel socio-económico y político que pudieron tener éste y otros "campos de silos" en las sociedades de la Prehistoria del sureste peninsular.

\section{AGRADECIMIENTOS}

Catalina Martínez Padilla (Universidad de Almería), Directora del proyecto I+D mencionado, consideró imprescindible autorizar la subvención de las muestras de TL. Ignacio Montero realizó el nuevo análisis de

Trab. Prehist., 75, N. ${ }^{\circ}$ 1, enero-junio 2018, pp. 67-84, ISSN: 0082-5638

https://doi.org/10.3989/tp.2018.12204 
restos de metalurgia de El Garcel. Así mismo agradecemos los datos y observaciones facilitados por Carmen Cacho, Aixa Vidal, María Molina, Arturo del Pino, Manuel Ramos, Asunción Millán, Pedro Beneitez, Jorge Morín y Primitivo Sanabria.

\section{BIBLIOGRAFÍA}

Acosta, P. 1976: "Excavaciones en el yacimiento de El Garcel. Antas (Almería)". Noticiario Arqueológico Hispánico 5: 189-191.

Alegre Frandovínez, I. 2005: "La industria geométrica en el Valle de Ambrona, Soria: materias primas, tecnología y tipología”. En P. Arias, R. Ontañón y C. García-Moncó (eds.): III Congreso del Neolítico en la Península Ibérica (Santander 2003): 233-245. Santander.

Aranda Jiménez, G.; Camalich Massieu, Mª D.; Martín, D.; Morgado, A.; Martínez-Sevilla, F.; Lozano Rodríguez, J. A.; Rodríguez Rodríguez, A.; Mancilla Cabello, M I I. y Román Punzón, J. 2012: La Loma (Íllora, Granada). Un yacimiento de fosas del VI-IV milenios cal BC. Monografías Arqueología. Junta de Andalucía, Consejería de Cultura. Sevilla.

Aranda Jiménez, G.; Lozano Medina, A.; Escudero Carrillo, J.; Sánchez Romero, M.; Alarcón García, E.; Fernández Martín, S.; Díaz-Zorita, M. y Barba Colmenero, V. 2016: "Cronología y temporalidad de los recintos de fosos prehistóricos: el caso de Marroquíes Bajos (Jaén)". Trabajos de Prehistoria 73 (2): 231-250. https://doi.org/10.3989/tp.2016.12171

Bernáldez, E.; Bernáldez, M. y García Viñas, E. 2013: “¿Campos de hoyos', campos de compost?: estudio tafonómico y paleobiológico del sector de La Gallega del yacimiento de Valencina de la Concepción (Sevilla)”. En L. García Sanjuán, J. M. Vargas Jiménez, V. Hurtado, T. Ruiz Moreno y R. Cruz-Auñón (eds.): El asentamiento prehistórico de Valencina de la Concepción (Sevilla). Investigación y tutela en el 150 aniversario del descubrimiento de La Pastora. Universidad de Sevilla. Sevilla: 421-444.

Blasco, C.; Galindo, L; Marcos Sánchez, V.; Ríos, P. y Liesau, C. 2016: "Ampliando el registro del Neolítico en el interior peninsular: ocupaciones inéditas en tres yacimientos de la región de Madrid". Del neolitic a l'edat del bronze en el Mediterrani occidental. Estudis en homenatge a Bernat Marti Oliver. Trabajos Varios del Servicio de Investigación Prehistórica del Museo de Prehistoria de Valencia 119. Valencia: 257-267.

Blasco, C.; Rubio, I.; Morales, A. y Jiménez, R. 1983: "Un nuevo yacimiento del Bronce madrileño: El Negralejo (Rivas-Vaciamadrid, Madrid)". Noticiario Arqueológico Hispánico 17: 43-190.

Cacho, C.; Fumanal, M. P.; López, P.; López, J. A.; Pérez Ripoll, M; Martínez Valle, R.; Uzquiano, P; Arnanz, A.; Sánchez Marco, A.; Sevilla, P; Morales, A.; Roselló, E.; Garralda, M. D. y García- Carrillo, M. 1995: "El Tossal de la Roca (Vall d'Alcalà, Alicante). Reconstrucción paleoambiental y cultural de la transición del Tardiglaciar al Holoceno inicial". Recerques del Museu d'Alcoi 4: 11-102.

Cardona, R.; Ferrer, C.; Morer, J.; Pou, J.; Asensio, D. y Tous, D. 2013: "Experimentació sobre emmagatzematge en sitges a Sant Esteve d'Olius (Solsona, Lleida). En A. Palomo, R. Piqué y X. Terradas (eds.): Experimentación en arqueología. Estudio y difusión del pasado. Sèrie Monogràfica del MAC-Girona 25.2. Girona: 309-317.

Castro Martínez, P. V.; Lull, V. y Micó, R. 1996: Cronología de la Prehistoria Reciente de la Península Ibérica y Baleares (c.2800-900 cal ANE). British Archaeological Reports, International Series 652, Tempus reparatum. Oxford.

Chapman, R. 1991: La formación de las sociedades complejas. El sureste de la Península Ibérica en el marco del Mediterráneo occidental. Editorial Crítica. Barcelona.

Chautón Pérez, H. 2010: "Intervención arqueológica en el yacimiento El Molino, T. M. de Huelves, en Cuenca. Noviembre 2006-Enero 2007". En A. Madrigal y M. Perlines (eds.): Actas de las II Jornadas de Arqueología de Castilla-La Mancha (Toledo 2006-2007) I: 408-427. Toledo.

Deramaix, I. 1992: La Collection Siret à Bruxelles. 1. Neolithique \& Chalcolithique. Musées Royaux d'Art et Histoire. Bruxelles.
Díaz-del-Río, P. 2013: "Las agregaciones de población del III milenio $\mathrm{aC}$ en la Península Ibérica". En L. García Sanjuán, J. M. Vargas Jiménez, V. Hurtado, T. Ruiz Moreno y R. Cruz-Auñón (eds.): El asentamiento prehistórico de Valencina de la Concepción (Sevilla). Investigación y tutela en el 150 aniversario del descubrimiento de La Pastora. Universidad de Sevilla. Sevilla: 65-76.

Díaz-del-Río, P.; Consuegra, S.; Peña Chocarro, L.; Márquez, B.; Sampedro, C.; Moreno, R.; Albertini, D. y Pino, B. 1997: "Paisajes agrarios prehistóricos en la Meseta peninsular: el caso de 'Las Matillas' (Alcalá de Henares, Madrid)". Trabajos de Prehistoria 54 (2): 93-111. https://doi.org/10.3989/tp.1997.v54.i2.368

Duque, D.; Pérez, G.; Pavón, I. y Rodríguez, A. 2009: “El almacenamiento en la Protohistoria del Guadiana medio: continentes y contenido". En R. García Huerta y D. Rodríguez González (eds.): Sistemas de almacenamiento entre los pueblos prerromanos peninsulares. Ed. Universidad de Castilla- La Mancha. Cuenca: 283-302.

Fernández Gómez, F. 2013: "Las excavaciones del Museo Arqueológico de Sevilla en Valencina de la Concepción (Sevilla) en 1975-1976: sectores de La Perrera, La Candelera y cerro de la Cabeza". En L. García Sanjuán, J. M. Vargas Jiménez, V. Hurtado, T. Ruiz Moreno y R. Cruz-Auñón (eds.): El asentamiento prehistórico de Valencina de la Concepción (Sevilla). Investigación y tutela en el 150 aniversario del descubrimiento de La Pastora. Universidad de Sevilla. Sevilla: $131-150$

García Puchol, O. 2006: "La piedra tallada del Abric de la Falguera". En O. García Puchol y J. E. Aura Tortosa (eds.): El abric de la Falguera (Alcoi, Alacant): 8.000 años de ocupación humana en la cabecera del río de Alcoi 2. Ediciones del Museo d'Alcoi. Alcoy: 260-295.

Gilman, A. 1997: "Cómo valorar los sistemas de propiedad a partir de datos arqueológicos". Trabajos de Prehistoria 54 (2): 81-92. https://doi.org/10.3989/tp.1997.v54.i2.367

Gossé, G. 1941: "Aljoroque, estación neolítica inicial de la provincia de Almería". Ampurias III: 63-84.

Gusi i Jener, F. y Olaria i Puyoles, C. 1991: El poblado neoeneolítico de Terrera-Ventura (Tabernas, Almería). Excavaciones Arqueológicas en España 160, Ministerio de Cultura. Madrid.

Lizcano, R.; Cámara, J. A.; Pérez Bareas, C. y Spanedda, L. 2005: "Continuidad en hábitat y continuidad ritual. Hipogeismo en el Alto Guadalquivir”. En P. Arias, R. Ontañón y C. García-Moncó (eds.): III Congreso del Neolítico en la Península Ibérica (Santander 2003): 653-662. Santander.

Maicas, R. 2007: Industria ósea y funcionalidad: Neolítico y Calcolítico en la Cuenca de Vera (Almeria). Bibliotheca Praehistorica Hispana 24, Editorial CSIC-CSIC. Madrid.

MAPA Ministerio de Agricultura, Pesca y Alimentación 1978: "Vera (Almería) 1014 (24-41)”. Memoria y Mapa de Cultivos y Aprovechamientos, 1:50.000. Servicio de Publicaciones Agrarias, Ministerio de Agricultura. Madrid.

Márquez Romero, J. E. 2013: "Yacimientos prehistóricos de fosos: una lectura alternativa a un problema histórico ya clásico". En L. García Sanjuán, J. M. Vargas Jiménez, V. Hurtado, T. Ruiz Moreno y R. Cruz-Auñón (eds.): El asentamiento prehistórico de Valencina de la Concepción (Sevilla). Investigación y tutela en el 150 aniversario del descubrimiento de La Pastora. Universidad de Sevilla. Sevilla: 77-92.

Márquez Romero, J. E. y Jiménez Jáimez, V. 2010: Recintos de foso. Genealogía y significado de una tradición en la Prehistoria del suroeste de la Península Ibérica (IV-III milenios AC). Servicio de Publicaciones de la Universidad de Málaga. Málaga.

Martín Nieto, P. 2001: "Documentación de la Colección Siret conservada en el Museo Arqueológico Nacional”. Boletín del Museo Arqueológico Nacional 19: 227-256.

Martínez Rodríguez, A. y Ponce García, J. 1997: "Excavaciones arqueológicas de urgencia en un enclave romano y un asentamiento del Neolítico Final en la calle Floridablanca, espalda Huerto Ruano (Lorca, Murcia)". Memorias de Arqueología 12: 291-306.

Mederos Martín, A. 1995: "La cronología absoluta de la Prehistoria Reciente del sureste de la Península Ibérica". Pyrenae 26: 53-90.

Miret i Mestre, J. 2006: "Sobre les sitges i altres estructures excavades al subsòl". Cypsela 16: 213-225.

Montero Ruiz, I. 1994: El origen de la metalurgia en el sureste peninsular. Instituto de Estudios Almerienses, Historia. Almería. 
Ollich, I; Rocafiguera, M.; Ocaña, M.; Cubero, C and Amblàs, O. 2012 : "Experimental Archaeology at L'Esquerda-Crops, storage, metalcraft and earthworks in Mediaeval and Ancient Times". En I. Ollich (ed.): Archaeology, New Approaches in Theory and Techniques. INTECH: 205-228. https://doi.org/10.5772/38790

Pujante Martínez, A. 1999: "El yacimiento prehistórico de Los Molinos de Papel (Caravaca de la Cruz, Murcia). Intervención arqueológica vinculada a las obras de infraestructura del Plan Parcial SCR2, 19992000". Memorias de Arqueología de la Región de Murcia 14: 133-172.

Pujante Martínez, A. 2011: "Estructuras del poblado calcolítico de Lorca en las excavaciones arqueológicas de la calle Juan II esquina calle Leonés". Alberca 9: 9-37.

Red Digital de Colecciones de Museos en España. Ministerio de Educación, Cultura y Deporte. http://ceres.mcu.es (consulta 2-12-2015)

Reynolds, P. J. 1998: "Les sitges subterrànies. The experimental storage of grain in simulated medieval underground silos". En I. Ollich, M. Rocafiguera y M. Ocaña (eds.): Experimentació Arqueològica sobre conreus medieval a l'Esquerda, 1991-1994. Monografies d'Arqueologia Medieval i postmedieval 3. Barcelona: 131-139.

Rodríguez Ariza, Ma O. 2000: "El paisaje vegetal de la Depresión de Vera durante la Prehistoria Reciente. Una aproximación desde la antracología". Trabajos de Prehistoria 57 (1): 145-156. https://doi.org/10.3989/tp.2000.v57.i1.266

Román Díaz, Ma P. 1996: Estudios sobre el Neolítico en el sureste de la Península Ibérica. Síntesis crítica y valoración. Servicio de $\mathrm{Pu}-$ blicaciones de la Universidad de Almería. Almería.

Román Díaz, M ${ }^{\text {a }}$ P. y Maicas Ramos, R. 2002: “'Campos de hoyos’ en la desembocadura del río Almanzora (Almería): Las Palas y La Era”. Complutum 13: 51-76.

Rovira Llorens, S. y Gómez Ramos, P. 1994: "Punzones y varillas metálicas en la Prehistoria reciente española: un estudio tecnológico". Espacio, Tiempo y Forma. Serie I, Prehistoria y Arqueología 7: 371-402.
Rubio de Miguel, I. 2004: "Rituales de cráneos y enterramientos en el Neolítico precerámico del Próximo Oriente". Cuadernos de Prehistoria y Arqueología de la Universidad Autónoma de Madrid 30: 27-46.

Salido Domínguez, J. 2009: "Transformaciones y evolución de los sistemas de almacenamiento y conservación de excedentes agrícolas desde la Edad del Hierro a la época romana”. En R. García Huerta y D. Rodríguez González (eds.): Sistemas de almacenamiento entre los pueblos prerromanos peninsulares. Ed. Universidad de Castilla-La Mancha. Cuenca: 103-116.

Sardá Piñero, D. 2013: "Estructuras negativas multifuncionales en Avenida de Andalucía no 9, Valencina de la Concepción (Sevilla)". En L. García Sanjuán, J. M. Vargas Jiménez, V. Hurtado; T. Ruiz Moreno y R. Cruz-Auñón (eds.): El asentamiento prehistórico de Valencina de la Concepción (Sevilla). Investigación y tutela en el 150 aniversario del descubrimiento de La Pastora. Universidad de Sevilla. Sevilla: 151-156.

Siret, L. 1999: "Caracteres industriales del Neolítico y del Eneolítico en el Sur de la Península Ibérica". En L. Siret y E. Siret: Del Neolítico al Bronce (compendio de estudios). Colección Luis Siret de Arqueología 6, Arráez Editores. Almería: 305-321. 1 a ed. 1931 en francés.

Siret, L. 2001: España Prehistórica. Junta de Andalucía. Arráez Editores. Almería. Ed. facsímil y traducida.

Siret, H. y Siret, L. 1890: Las Primeras Edades del Metal en el Sudeste de España. Henrich y $\mathrm{C}^{\mathrm{a}}$. Barcelona.

Torija, A; Baquedano, I. y Cruz, M. 2010: "Inhumaciones infantiles en el centro peninsular durante la Protohistoria. Algunas novedades en el yacimiento de Cerrocuquillo". En F. Burillo (ed.): Actas del VI Simposio sobre Celtiberos: Ritos y Mitos (Zaragoza 2008): 434-444. Zaragoza.

Vicent García, J. M. 1991: "El neolítico. Transformaciones sociales y económicas". Boletín de Antropología Americana 24: 31-62.

Trab. Prehist., 75, N. ${ }^{\circ}$ 1, enero-junio 2018, pp. 67-84, ISSN: 0082-5638

https://doi.org/10.3989/tp.2018.12204 